\title{
$\$$ Research Square \\ Parameter estimation of different solar cells using a swarm intelligence technique
}

Jyoti Gupta

Thapar Institute of Engineering and Technology

\section{Parag Nijhawan}

Thapar Institute of Engineering and Technology

Souvik Ganguli ( $\sim$ souvik.ganguli@thapar.edu )

Thapar Institute of Engineering \& Technology https://orcid.org/0000-0003-4192-398X

\section{Research Article}

Keywords: Diode modelling, Chicken swarm optimization, Chaotic maps, I-V and P-V curve, Error analysis, Statistical tests.

Posted Date: July 20th, 2021

DOI: https://doi.org/10.21203/rs.3.rs-371558/v1

License: @ (i) This work is licensed under a Creative Commons Attribution 4.0 International License. Read Full License 


\title{
Parameter estimation of different solar cells using a novel swarm intelligence technique
}

\author{
Jyoti Gupta ${ }^{1}$, Parag Nijhawan ${ }^{2}$, Souvik Ganguli ${ }^{3}$ \\ Department of Electrical and Instrumentation Engineering, Thapar Institute of Engineering \\ and Technology, Patiala-147004, Punjab, India \\ Corresponding author email: souvik.ganguli@thapar.edu
}

\begin{abstract}
Since the demand for a clean source of energy has increased, it led to the consequent rise in the importance of solar energy. Thus, the concept of solar cell modelling has drawn the attention of various researchers across the world. A useful and accurate mathematical model for such cells is therefore necessary. In the literature, the three-diode model (TDM) is suggested as a more reliable approach to satisfy the behaviour of photovoltaic (PV) cells. This paper proposes a new swarm intelligent technique namely, the Chaotic Chicken Swarm Optimization (CCSO), which is originated from the parent chicken swarm algorithm, for parameter assessment of the three-diode PV model, as the three-diode PV model incorporate the grain boundaries and leakage current. Ten different popular chaotic maps have been considered for the study to identify the parameters from the manufacturer datasheet. The chicken swarm technique yields great optimization results both in terms of accuracy and robustness. Further, the use of chaotic maps improves the diversification feature of this metaheuristic technique for which it is preferred. The performance of the proposed approach proved better when compared with some of the popular techniques available in the literature in terms of convergence accuracy and speed. The accuracy of the proposed technique is also verified by extracting I-V and P-V curves. Moreover, several non-parametric statistical tests are also performed to validate the significance of the outcomes obtained by the proposed method.
\end{abstract}

Keywords: Diode modelling, Chicken swarm optimization, Chaotic maps, I-V and P-V curve, Error analysis, Statistical tests.

\section{Introduction}

Through previous years, renewable energy is regarded as a very efficient alternative to fossil fuel to meet the rising energy demand. Solar energy is the primary energy source among various renewable energy resources due to its sufficient availably across the world [1-2]. Photovoltaics has attained immense attention nowadays [3]. Precise modelling and detailed knowledge are thus required for photovoltaic systems such as the effect of partial shading [4], 
extraction of maximum power, operating conditions like stand-alone or grid-connected [5] etc., under different environmental conditions [6].

The output power of the PV system is highly nonlinear i.e., it produces varying power with the change in voltage and current with respect to environmental conditions [7]. Therefore, the PV system should be operated at MPP for maximum efficiency [8]. PV standard values like open-circuit voltage $\left(V_{\text {open }}\right)$, short circuit current $\left(\mathrm{I}_{\text {short }}\right)$, saturation current $\left(\mathrm{I}_{\mathrm{d}}\right)$, photocurrent $\left(I_{p v}\right)$, diode ideality factor $(n)$, series resistance $\left(R_{s e}\right)$, and shunt resistance $\left(R_{p}\right)$ are needed to obtain the appropriate parameter values. But sometimes PV module manufacture does not provide some vital information such as saturation current $\left(I_{d}\right)$, photocurrent $\left(I_{p v}\right)$, diode ideality factor $(n)$, series resistance $\left(R_{s e}\right)$, and shunt resistance $\left(R_{p}\right)$ [9].

The single diode solar model (SDM) and the double diode solar model (DDM) is generally used PV models for extracting the electrical parameters [10-11]. The single diode model is the basic PV model with the highest degree of precision which required only five common unknown parameters (PV current $I_{p v}$, diode saturation current $I_{d}$, ideality factor $n$, series resistance $R_{s e}$, and shunt resistance $R_{p}$ ) to predict the output I-V curve [12]. However, the main drawback of the single diode PV model is that it does not consider the recombination losses in the depletion region. So to overcome this disadvantage, the double diode PV model was addressed [13]. In the double diode model, to define recombination losses in the PV cell, an addition diode was introduced in the basic single diode model [14]. The effect of diode leakage current and grain boundaries can be addressed using three diode model PV systems and it includes nine parameters to be extracted [15-16]. There is relatively limited research on the three diode model (TDM) owing to the higher degree of difficulty and the rise in the number of unknown parameters $[8,17]$.

The parameter estimation of renewable energy is referred to as the optimization problem. Various approaches like analytical method, metaheuristic methods, and combination of metaheuristics and analytical methods are addressed by different researchers to extract the unknown electrical parameter of the PV model [18]. The manufacturer data of the PV module provides the value of the basic components of the equation at standard conditions and operating conditions. In the analytical method, unknown parameters of the PV model are extracted utilizing the I-V curve data and data sheets information [19]. These methods suffer problems in extracting the value of parameters of complex models like modified two diodes and three diodes and sometimes even consider the initial values or ignore the resistive effect which results in inaccurate parameters [20]. Due to these various drawbacks, the metaheuristic method was introduced [21]. In the combination of metaheuristic and analytical 
methods, parameter estimation of the solar cells is carried out, where one or two parameters are extracted using the analytical approach, and the rest are extracted using a metaheuristic approach.

The metaheuristic optimization technique operates with the principle of optimizing the random particles in the defined space to obtain the fitness function through a repetitive process. The most commonly used error objective function in literature is the root mean square error (RMSE) [22]. Previously, various metaheuristic techniques have been implemented successfully by researchers for PV parameter extraction such as salp swarm algorithm (SSA) [23], wind-driven optimization (WDO) [24], and moth-flame optimizer (MFO) [25], fireworks algorithm [26], artificial immune system [27]. Nowadays many researchers have also introduced modified algorithms like the chaotically improved artificial bee colony (CIABC), and the chaotic variant of whale optimization algorithm (CWOA) [28], Fractional Chaotic Ensemble Particle Swarm Optimizer (FC-EPSO) [29], Modified Elephant Swarm Water Search Algorithm (MESWSA) [30]. A Niche-based Particle Swam Optimization in parallel computing architecture was also presented by the authors in [31].

Thus, it is observed from the literature, that researchers mainly considered the basic model of PV i.e. single diode model (SDM) and double diode model (DDM) for electrical parameter estimation. Very little research is being performed on the three diode models (TDM) [15] due to a higher degree of complexity with the increase in the number of unknown parameters. However, these models justified their efficiency and accuracy in multi-crystalline solar cells more than the basic model. The conventional optimization algorithm was used on the rooster has the fittest value among chicken and TDM as provided in the literature which consumes greater time in processing. So, a more efficient algorithm with more accuracy should be proposed from parameter extraction to these advanced models.

Chaos theory-based optimization algorithms are stochastic search techniques that are distinct from conventional evolutionary computing and swarm intelligence methods. Because chaos is non-repeatable, it can perform overall searches faster than stochastic ergodic searches based on probability. In this situation, chaotic optimization techniques can escape from local minima more quickly than other stochastic optimization and direct search algorithms. The major benefit of chaotic optimization techniques in CCSO design is that they preserve population variety in the problem of interest. The approaches that employ chaotic variables rather than random variables are termed chaotic optimization algorithms (COA) [32-33]. 
In this paper, CCSO is proposed to estimate the unknown parameters of TDM. Ten chaotic maps popular in the literature are employed to improve the performance of the chicken swarm optimization algorithm. Three commercial PV models, popularly reported in the literature, are taken for the study. The parameter estimation has been carried out using the datasheet information of the PV models. The Sum of Square Error (SSE) is considered as the objective function for the evaluation of diode model parameters. The choice is competitive with the RMSE, widely used in the literature with experimental data set. The normalized value of the error function is tabulated and the convergence graphs are drawn to show the speed and accuracy of the proposed method over the existing algorithms. The statistical measures of the error function (minimum, maximum, average, and standard deviation) have also been presented since the algorithms used are stochastic. Extensive non-parametric statistical tests viz. the Wilcoxon rank-sum test [34], Kruskal-Wallis test [35], and Wilcoxon rank-sum test with Holm-Bonferroni corrections [36] are also performed to validate the results. The I-V and P-V curves obtained from the estimated parameters justify the accuracy of the proposed method.

The remaining article is arranged with the succeeding flow of topics as follows. Section 2 discusses the modelling equations of the different photovoltaic models as well as states the problem under consideration in this work. Section 3 deliberates upon the proposed methods. Section 4 showcases the results obtained for the different commercial solar cells. Finally, the major inferences and future scope of work have been highlighted in Section 5.

\section{Basic PV cell modelling and problem statement}

\subsection{Single diode model (SDM)}

Different diode models have been used to explore the characteristics of PV. Most common and popular in the literature is the single-diode model, abbreviated as SDM, and is represented with the help of Fig. 1. 


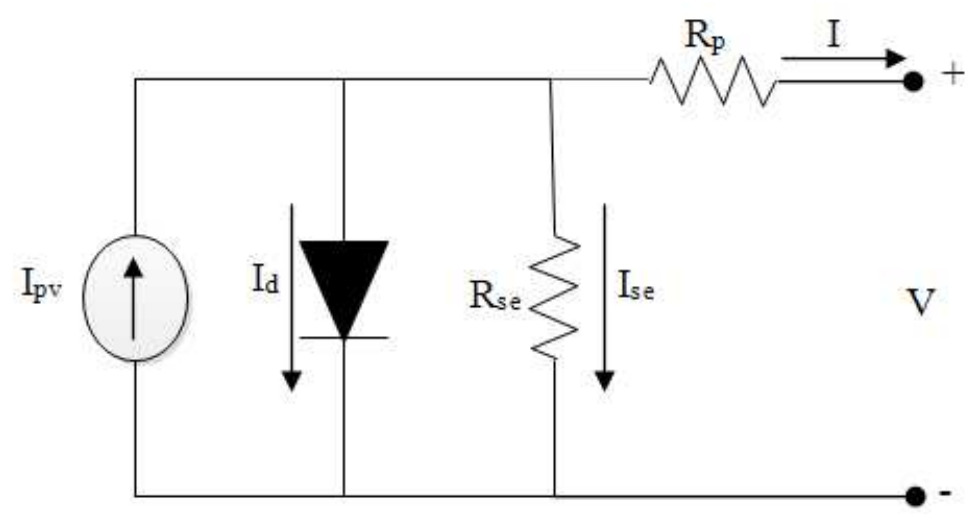

Fig. 1. The equivalent circuit representation for a single diode model

Mathematically, the output current can be represented as

$$
I=I_{p v}-I_{d}\left[\exp \left(\frac{q\left(V+I R_{s e}\right)}{n K T}\right)-1\right]-\frac{V+I R_{s e}}{R_{p}}
$$

where

$I_{P V}, I_{D}$ and $I$ is Photovoltaic current, saturation current, output current $(A)$, respectively

$q$

k Boltzmann's Constant $k=1.381 \times 10-23(\mathrm{~J} / K)$

T PV cell temperature $(\mathrm{K})$

V Voltage of PV cell (V)

To obtain the five unknown parameters $\left(I_{p v}, I_{d}, n, R_{s e}, R_{p}\right)$, the open circuit, short circuit, and maximum power point equations are used as given below.

At the condition of the open circuit, the output current (I) is equivalent to zero whereas the output voltage represents open-circuit voltage given by $\mathrm{V}_{\text {open }}$; then eq. (1) can be depicted as;

$$
0=I_{p v}-I_{d}\left[\exp \left(\frac{q V_{o p e n}}{n K T}\right)-1\right]-\frac{V_{o p e n}}{R_{p}}
$$

Therefore;

$$
I_{p v}=I_{d}\left[\exp \left(\frac{q V_{o p e n}}{n K T}\right)-1\right]+\frac{V_{o p e n}}{R_{p}}
$$

At the time of the short circuit, the output current equals the short circuit current denoted by Ishort while the output voltage represents zero; then eq. (1) can be depicted as;

$$
I_{\text {short }}=I_{p v}-I_{d}\left[\exp \left(\frac{q_{\text {open }} R_{s e}}{n K T}\right)-1\right]-\frac{I_{\text {short }} R_{s e}}{R_{p}}
$$

Therefore; 


$$
I_{p v}=I_{\text {short }}+I_{d}\left[\exp \left(\frac{q I_{\text {short }} R_{s e}}{n K T}\right)-1\right]+\frac{I_{\text {short }} R_{s e}}{R_{p}}
$$

During the condition of the maximum power point, output current (I) is equivalent to maximum current $\left(I_{\max }\right)$ and output voltage represents the maximum voltage $\left(V_{\max }\right)$; then eq. (1) can be depicted as;

$$
I_{\max }=I_{p}-I_{d}\left[\exp \left(\frac{q\left(V_{\max }+I_{\max } R_{s e}\right)}{n K T}\right)-1\right]-\frac{V_{\max }+I_{\max } R_{s e}}{R_{p}}
$$




\subsection{Double Diode Model (DDM)}

The refined version of SDM is the Double Diode Model (DDM). In DDM, an additional diode is incorporated in parallel with the basic SDM which represents the space charge recombination. The equivalent circuit of DDM is thus shown with the help of Fig. 2.

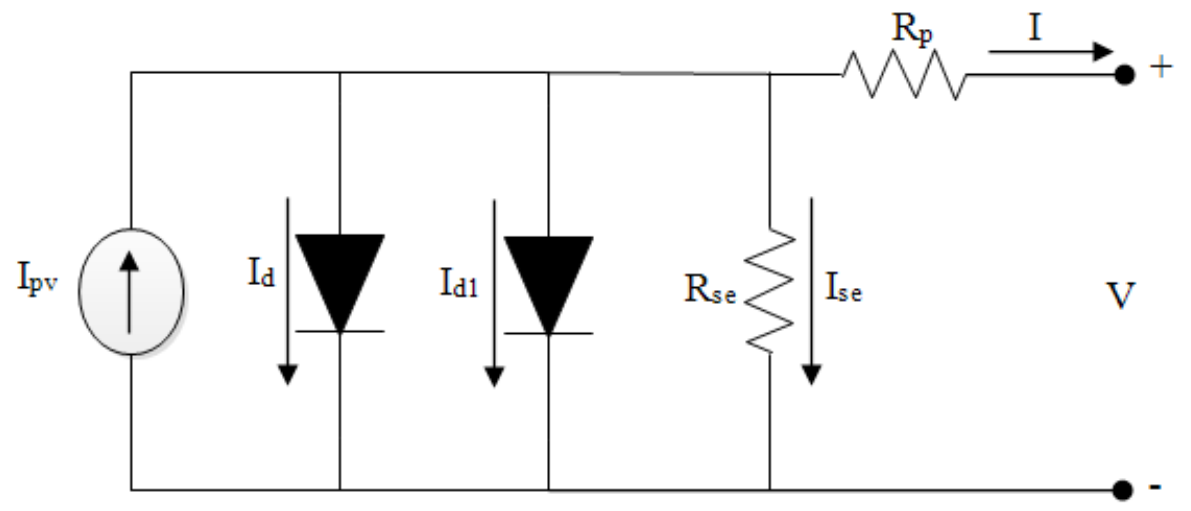

Fig. 2. The representation of a double-diode model for a photovoltaic system.

From the diagram displayed in Fig. 2, the output current (I) equation of the double diode model is represented by

$$
I=I_{p v}-I_{d}\left[\exp \left(\frac{q\left(V+I R_{s e}\right)}{n K T}\right)-1\right]-I_{d 1}\left[\exp \left(\frac{q\left(V+I R_{s e}\right)}{n_{1} K T}\right)-1\right]-\frac{V+I R_{s e}}{R_{p}}
$$

where $I_{d 1}, n_{1}$ is the reverse saturation current and ideality factor for the new diode.

Seven undefined DDM parameters need to be extracted that are $I_{p v}, I_{d}, n, R_{s e}, R_{p}, I_{d 1}, n_{1}$. Thus, we find two extra parameters as compared with SDM. The other equations can be modified accordingly and described below.

During the condition of the open circuit, the output current (I) is equivalent to zero while the output voltage represents the open-circuit voltage $\left(\mathrm{V}_{\text {open }}\right)$; then eq. (7) can be depicted as;

$$
0=I_{p v}-I_{d}\left[\exp \left(\frac{q V_{\text {open }}}{n K T}\right)-1\right]-I_{d 1}\left[\exp \left(\frac{q V_{\text {open }}}{n_{1} K T}\right)-1\right]-\frac{V_{\text {open }}}{R_{p}}
$$

Therefore;

$$
I_{p v}=I_{d}\left[\exp \left(\frac{q V_{o p e n}}{n K T}\right)-1\right]+I_{d 1}\left[\exp \left(\frac{q V_{o p e n}}{n_{1} K T}\right)-1\right]+\frac{V_{o p e n}}{R_{p}}
$$

At the instant of a short circuit, the current equals the short circuit current given by $\mathrm{I}_{\text {short }}$ and the voltage is zero; then eq. (7) can be depicted as; 


$$
I_{\text {short }}=I_{p v}-I_{d}\left[\exp \left(\frac{q I_{\text {short }} R_{s e}}{n K T}\right)-1\right]-I_{d 1}\left[\exp \left(\frac{q I_{\text {short }} R_{s e}}{n_{1} K T}\right)-1\right]-\frac{I_{\text {short }} R_{s e}}{R_{p}}
$$

Therefore;

$$
I_{p v}=I_{\text {short }}+I_{d}\left[\exp \left(\frac{q I_{\text {short }} R_{s e}}{n K T}\right)-1\right]+I_{d 1}\left[\exp \left(\frac{q I_{\text {short }} R_{s e}}{n_{1} K T}\right)-1\right]+\frac{I_{\text {short }} R_{s e}}{R_{p}}
$$

At the time of the maximum power point, the output current (I) is equivalent to maximum current $\left(I_{\max }\right)$ and output voltage represents the maximum voltage $\left(V_{\max }\right)$; then eq. (7) can be depicted as;

$$
I_{\max }=I_{p}-I_{d}\left[\exp \left(\frac{q\left(V_{\max }+I_{\max } R_{s e}\right)}{n K T}\right)-1\right]-I_{d 1}\left[\exp \left(\frac{q\left(V_{\max }+I_{\max } R_{s e}\right)}{n_{1} K T}\right)-1\right]-\frac{V_{\max }+I_{\max } R_{s e}}{R_{p}}
$$

\subsection{Three diode model}

In the three-diode model (TDM), three diodes are put in a parallel arrangement for the PV cell model as represented in Fig. 3. The third diode considers the effect of leakage current and grain boundaries.

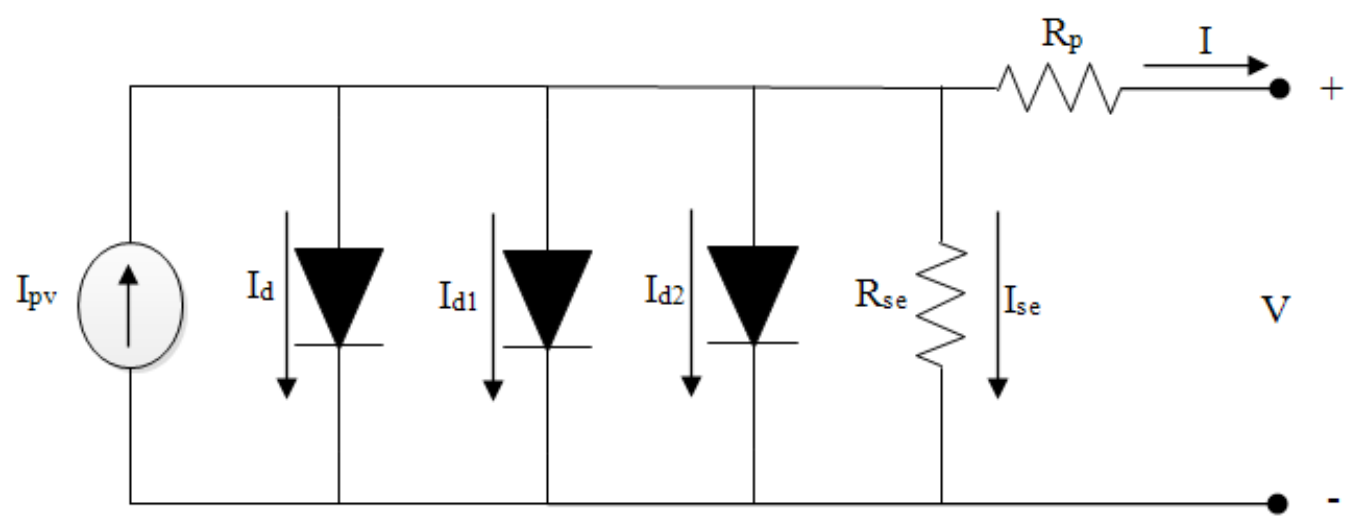

Fig. 3. The representative circuit for a three-diode model.

The current equation of the TDM is thus formulated as

$$
I=I_{p v}-I_{d}\left[\exp \left(\frac{q\left(V+I R_{S e}\right)}{n K T}\right)-1\right]-I_{d 1}\left[\exp \left(\frac{q\left(V+I R_{S e}\right)}{n_{1} K T}\right)-1\right]-I_{d 2}\left[\exp \left(\frac{q\left(V+I R_{S e}\right)}{n_{2} K T}\right)-1\right]-\frac{V+I R_{S e}}{R_{p}}
$$

The nine unidentified parameters of TDM to be extracted are $I_{p v}, I_{d}, n, I_{d 1}, n_{1}, I_{d 2}, n_{2}, R_{s e}, R_{p}$. Once again, there are two extra parameters as compared to DDM. In this paper, the TDM of 
PV cells has been considered to enhance the accuracy of the estimation technique. The other equations can be modified accordingly and described below.

At the time of an open circuit, the output current (I) is equivalent to zero and output voltage represents the open-circuit voltage $\left(\mathrm{V}_{\text {open }}\right)$; then eq. (13) can be depicted as;

$$
0=I_{p v}-I_{d}\left[\exp \left(\frac{q V_{\text {open }}}{n K T}\right)-1\right]-I_{d 1}\left[\exp \left(\frac{q V_{\text {open }}}{n_{1} K T}\right)-1\right]-I_{d 2}\left[\exp \left(\frac{q V_{\text {open }}}{n_{2} K T}\right)-1\right]-\frac{V_{\text {open }}}{R_{p}}
$$

Therefore;

$$
I_{p h}=I_{d}\left[\exp \left(\frac{q V_{\text {open }}}{n K T}\right)-1\right]+I_{d 1}\left[\exp \left(\frac{q V_{\text {open }}}{n_{1} K T}\right)-1\right]+I_{d 2}\left[\exp \left(\frac{q V_{\text {open }}}{n_{2} K T}\right)-1\right]+\frac{V_{\text {open }}}{R_{p}}
$$

During the short circuit conditions, the output current (I) is equivalent to short circuit current (Ishort) and output voltage represents to zero; then eq. (13) can be depicted as;

$$
\begin{array}{r}
I_{\text {short }}=I_{p v}-I_{d}\left[\exp \left(\frac{q I_{\text {short }} R_{s e}}{n K T}\right)-1\right]-I_{d 1}\left[\exp \left(\frac{q I_{\text {short }} R_{s e}}{n_{1} K T}\right)-1\right]-I_{o 2}\left[\exp \left(\frac{q I_{\text {short }} R_{s e}}{n_{2} K T}\right)-\right. \\
1]-\frac{I_{\text {short }} R_{s e}}{R_{p}}
\end{array}
$$

Therefore;

$$
\begin{gathered}
I_{p v}=I_{\text {short }}+I_{d}\left[\exp \left(\frac{q I_{\text {Short }} R_{s e}}{n K T}\right)-1\right]+I_{d 1}\left[\exp \left(\frac{q I_{\text {short }} R_{s e}}{n_{1} K T}\right)-1\right]+I_{d 2}\left[\exp \left(\frac{q I_{\text {short }} R_{s e}}{n_{2} K T}\right)-\right. \\
1]+\frac{I_{\text {short }} R_{s e}}{R_{p}}
\end{gathered}
$$

At the instant of the maximum power point, the output current (I) is equivalent to maximum current $\left(\mathrm{I}_{\max }\right)$ and output voltage represents the maximum voltage $\left(\mathrm{V}_{\max }\right)$; then eq. (13) can be depicted as;

$$
\begin{array}{r}
I_{\max }=I_{p}-I_{d}\left[\exp \left(\frac{q\left(V_{\max }+I_{\max } R_{s e}\right)}{n K T}\right)-1\right]-I_{d 1}\left[\exp \left(\frac{q\left(V_{\max }+I_{\max } R_{s e}\right)}{n_{1} K T}\right)-1\right]- \\
I_{d 1}\left[\exp \left(\frac{q\left(V_{\max }+I_{\max } R_{s e}\right)}{n_{2} K T}\right)-1\right]-\frac{V_{\max }+I_{\max } R_{s e}}{R_{p}}
\end{array}
$$

\subsection{Problem formulation}

The problem taken up in this investigation is to extract the parameters of the photovoltaic cell. Several error functions have been considered for the formulation of its objective function to assess the parameters of the solar cell. The most popular is the root mean square error (RMSE). Mostly this error function is taken up as the objective function for parameter estimation using the experimental condition information of the PV model. In this objective 
function, some parameters are also identified analytically as well. Biswas et al. [8] adopted the sum of squares (SSE) for the first time as the objective to estimate the anonymous parameters of the single and the double diode models from the datasheet information of different PV cells. This work has been extended in this paper by formulating the SSE for the assessment of the three-diode model parameters. A new swarm intelligent technique namely, the chaotic chicken swarm optimization (CCSO), deliberated in Section 3, is developed for this purpose. The three main conditions, mentioned earlier, are employed to reduce the error using the proposed technique. Thus, the open-circuit error equation is presented as

$$
\operatorname{err}_{\mathrm{OC}}=I_{o}\left[\exp \left(\frac{q V_{O C}}{\alpha K T}\right)-1\right]+I_{o 1}\left[\exp \left(\frac{q V_{O C}}{\alpha_{1} K T}\right)-1\right]+I_{o 2}\left[\exp \left(\frac{q V_{O C}}{\alpha_{2} K T}\right)-1\right]+\frac{V_{O C}}{R_{S h}}-I_{p h}
$$

The short circuit error equation is given by

$$
\operatorname{err}_{\mathrm{SC}}=I_{S C}+I_{o}\left[\exp \left(\frac{q I_{S C} R_{S}}{\alpha K T}\right)-1\right]+I_{o 1}\left[\exp \left(\frac{q I_{S C} R_{S}}{\alpha_{1} K T}\right)-1\right]+I_{o 2}\left[\exp \left(\frac{q I_{S C} R_{S}}{\alpha_{2} K T}\right)-1\right]+\frac{I_{S C} R_{S}}{R_{S h}}-I_{p h}
$$

Finally, the maximum power point error equation is denoted as

$$
\operatorname{err}_{\mathrm{MP}}=I_{s h}-I_{o}\left[\exp \left(\frac{q\left(V_{m p}+I_{m p} R_{S}\right)}{\alpha K T}\right)-1\right]-I_{o 1}\left[\exp \left(\frac{q\left(V_{m p}+I_{m p} R_{S}\right)}{\alpha K T}\right)-1\right]-I_{o 1}\left[\exp \left(\frac{q\left(V_{m p}+I_{m p} R_{S}\right)}{\alpha K T}\right)-1\right]-
$$

The SSE constitutes the objective function and its equation is given by Eq. (22) as follows.

$$
e r r=e r r_{O C}^{2}+e r r_{S C}^{2}+e r r_{M P}^{2}
$$

The main purpose of the suggested methodology is to obtain the three diode model parameters by minimizing the square error. The heuristic suggested is therefore based on the minimization of the fitness function with respect to the bounds of the parameter.

\section{Proposed methodology}

After the problem formulation in section-2, the method adopted to estimate the parameters of the TDM is discussed in this section. To set an appropriate background for the readers, the chicken swarm optimization (CSO) and the chaos theory are deliberated. Then the chaotic chicken swarm optimization (CCSO) is presented.

\subsection{Chicken swarm optimization}

Chicken swarm optimization (CSO) is a newly developed metaheuristic bio-inspired algorithm [37]. CSO is inspired by the behaviours and the hierarchical structure of a swarm of chickens during the food search, where individual chicken denotes a possible solution to an optimization problem. For simplicity, to idealize the behaviour of chickens the mentioned algorithm assumes the following four rules, which are described below. 
(1) Swam of chicken is mainly comprised of several groups. Each group comprises a dominant rooster and a couple of hens and chicks.

(2) Fitness values of the chicken swam lead to the formation of groups and their identification as rooster, hen, and chicks. The rooster is the group head so the chicken with the fittest value is declared as the group head or rooster of a particular group. The chickens with the poorest fittest value would be declared as chicks and the rest chicken is declared as hens. Further, the number of chicks should be less than the number of hens.

(3) Rooster and hen relationships are established randomly so the hen could choose any group randomly to stay within. Similarly, the mother hens and child chick relationship is also established abruptly. The hierarchal order, dominance relationship, and mother-child relationship in each group will remain touched within $G$ iterations. Every update in their statues takes place after several time iterations to uphold the population diversity and to reduce any chance of local convergence.

(4) Hens follow their dominant rooster and chick follow their mother hen for the search of food, though they may preclude the ones from eating their food. It is assumed that the dominant rooster of each group would arbitrarily rob the good food that is already found by another rooster.

Further, $R N, H N, C N$, and $M N$ represent the number of roosters, the hens, the chicks, and the mother hens, respectively. The rooster has the fittest value among chickens, so it is presumed to be the head of the rooster of the group, where the $C N$ is the worst ones so it would be referred to as chicks. The left ones are assumed as hens. The population size is denoted by N, individual dimension is denoted by $\mathrm{D}$ and individual position can be represented by $x_{i}^{j}(t)\left(i \in[1, \cdots, N], j \in[1, \cdots, D]\right.$ in the $\mathrm{t}^{\text {th }}$ iteration.

The position update of the rooster could be described as follows:

$$
\begin{gathered}
x_{i}^{j}(t+1)=x_{i}^{j}(t) *\left[1+N\left(0, \sigma^{2}\right)\right] \\
\sigma^{2}=\left\{\begin{array}{cc}
1 & f_{i} \leq f_{k} \\
\exp \left[\frac{\left(f_{k}-f_{i}\right)}{\left|f_{i}+\varepsilon\right|}\right] & \text { otherwise }
\end{array}\right\} \\
k \in[1, R N], k \neq i
\end{gathered}
$$

Where $N\left(0, \sigma^{2}\right)$ is the Gaussian distribution and 0 is the mean and $\sigma^{2}$ is the variance, $\varepsilon$ denotes the smallest constant, ' $k$ ' symbolizes the index of the rooster from further groups, ' $\mathrm{f}$ ' symbolizes the fitness index of the individual chicken correspondingly.

The updated position of hens could be described as below:

$$
x_{i}^{j}(t+1)=x_{i}^{j}(t)+S_{1} * \operatorname{rand} *\left[x_{r 1}^{j}(t)-x_{i}^{j}(t)\right]+S_{2} * \operatorname{rand} *\left[x_{r 2}^{j}(t)-x_{i}^{j}(t)\right]
$$




$$
\begin{aligned}
S_{1}=\exp \left\{\frac{\left(f_{i}-f_{r 1}\right)}{\left[a b s\left(f_{i}\right)+\varepsilon\right]}\right\} \\
S_{2}=\exp \left(f_{r 2}-f_{i}\right)
\end{aligned}
$$

where rand represents a uniformly distributed random integer within the range $[0,1], r 1 \in$ $[1, \cdots, N]$ is an index of the rooster that is the hen $\mathrm{i}^{\text {th }}$ group-mate, $r 2 \in[1, \cdots, N]$ is an index of the chicken that is randomly picked from the swarm and $r_{1} \neq r_{2}$.

The updated position of chicks could be denoted by

$$
x_{i}^{j}(t+1)=x_{i}^{j}(t)+F L \times\left[x_{m}^{j}(t)-x_{i}^{j}(t)\right]
$$

where $m$ indicates the mother hen of the $i^{t^{h}}$ chick and FL is a parameter that implies the chick would follow their mother for foraging of food. Considering the individual differences, the value of $F L$ for each chick is made to vary between 0 and 2 .

\subsection{Chaos theory}

In a nonlinear system, chaos is a deterministic and random process that refers to initial conditions. The behaviour of the nonlinear system will dramatically change if there are small changes in the initial values. Besides, a chaotic system has complex characteristics such as certainty, randomness, and sensitivity initial conditions, and even a good internal structure. Based on these features, the diversity of the population should be retained and therefore prevent entering into an optimum local search and improve the probability of reaching a global optimum [38].

The chaos theory as a dynamic system can be presented as:

$$
c p_{k+1}^{i}=f\left(c p_{k}^{i}\right), \quad i=1,2,3 \ldots n
$$

where ' $\mathrm{n}$ ' refers to the dimension of the map. $f\left(c p_{k}^{i}\right)$ is the function that generates a chaotic model. Various kinds of such maps are used in the literature [37] which are represented in Table 1 .

Table 1. The list of chaotic maps.

\begin{tabular}{ll}
\hline Map Name & Definition \\
\hline Chebyshev map & $x_{k+1}=\cos \left(k \cos ^{-1}\left(x_{k}\right)\right)$ \\
Circle map & $x_{k+1}=x_{k}+\mathrm{b}-(\mathrm{a}-2 \pi) \sin \left(2 \pi x_{k}\right) \bmod (1)$ \\
Gauss map & $x_{k+1}=\left\{\begin{array}{cc}0 & x_{k}=0 \\
1 / x_{k} \bmod (1) & \text { otherwise }\end{array}\right\}$ \\
Iterative map & $x_{k+1}=\sin \left(a \pi / x_{k}\right)$ \\
Logistic map & $x_{k+1}=a x_{k}\left(1-x_{k}\right)$ \\
\hline
\end{tabular}




\begin{tabular}{ll}
\hline & \\
$x_{k+1}=\left\{\begin{array}{cc}\frac{x_{k}}{P} & 0 \leq x_{k}<P \\
\frac{x_{k}-P}{0.5-P} & P \leq x_{k}<0.5 \\
\frac{1-P-x_{k}}{0.5-P} & 0.5 \leq x_{k}<1-P \\
\frac{1-x_{k}}{P} & 1-P \leq x_{k}<1\end{array}\right\}$ \\
Piecewise map \\
Sine map \\
Singer map \\
Sinusoidal map \\
Tent map \\
$x_{k+1}=\frac{a}{4} \sin \left(\pi x_{k}\right)$ \\
$x_{k+1}=\mu\left(7.86 x_{k}-23.31 x_{k}^{2}+28.75 x_{k}^{3}-13.3028 .75 x_{k}^{4}\right.$ \\
$x_{k+1}=\left\{\begin{array}{cc}\frac{x_{k}^{2} \sin \left(\pi x_{k}\right)}{0.7} x_{k}<0.7 \\
\frac{10}{3}\left(1-x_{k}\right) & x_{k} \geq 0.7\end{array}\right\}$ \\
\hline
\end{tabular}

\subsection{New chaotic chicken swarm optimization (CCSO) technique}

The benefit of the chaotic maps in metaheuristic algorithms is well explored [40-42] in the literature. Chicken swarm optimization is no exception to this. As being a swarm-based algorithm, CSO supports greatly extendibility. In CCSO design, the main advantage of chaotic optimization approaches is maintaining the population diversity in the problem of interest. There are already two chaotic algorithms reported for the chicken swarm strategy [43-44]. In the former, the problem of the CSO is to get stuck in the local minimum which is eliminated with the help of logistic and tent maps to assist the CSO algorithm to explore the search space in a better way [43]. In [44], the tent map was only applied to obtain the best candidate solution of the chicken swarm using a local search, and the chosen individual had thereby been replaced by the randomly selected rooster. So, the benefit of only two chaotic maps has been tested so far in CSO. In this paper, the parameter $F L$ (a parameter that implies the chick would follow their mother for foraging of food) is used in eq. (28) of the classical CSO method, is varied chaotically using the ten maps denoted in Table 1 to yield better results as compared to the original approach. This variation of $F L$ diversifies the search solution and helps to yield better solution as compared to the existing chaotic versions of CSO. The pseudo-code of the proposed technique is shown in Fig. 4 for a better understanding of the readers. 


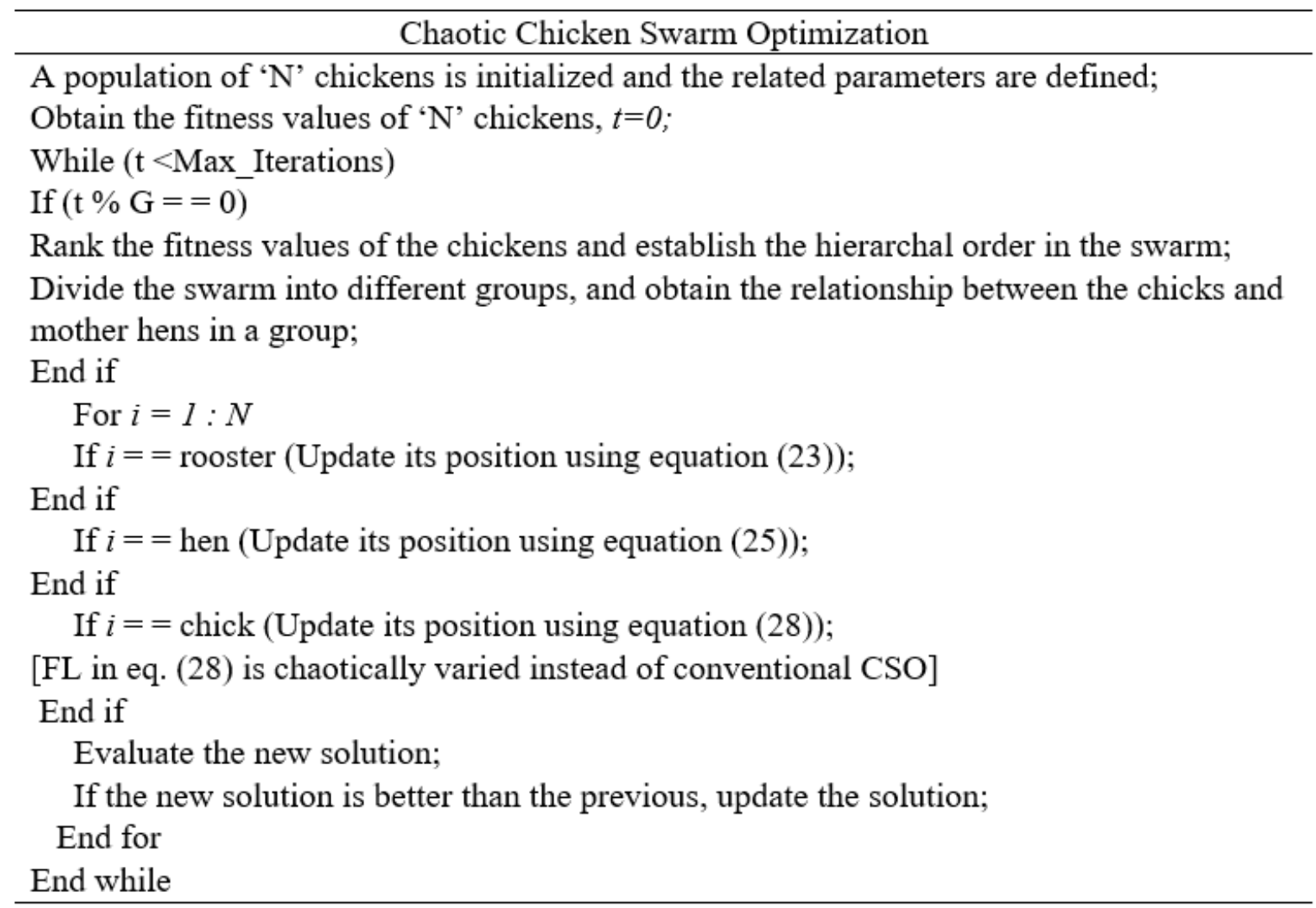

Fig. 4. Pseudocode of chaotic chicken swarm optimization (CCSO).

These new algorithms are further employed to estimate the TDM of different solar cells discussed in section-4.

\section{Simulation results and discussions}

In this section of the paper, three famous commercial modules are utilized for the estimation of the parameters of the TDM model. In this regard, the practical PV modules are CS6K 280M [22], KC200GT [11], and MSX-60 [11], which are fabricated by Canadian, Kyocera, and Solarex, respectively. Table 2 illustrates the values of the electrical performance of the mentioned commercial PV modules under the STC condition.

Table 2. Datasheet values of PV modules at STC conditions.

\begin{tabular}{llll}
\hline Company & Canadian solar & Kyocera & Solarex \\
\hline Model & CS6K-280M & KC200GT & MSX-60 \\
Cell type & Mono-crystalline & Multicrystal & Poly-crystalline \\
Pm [W] & 280 & 200 & 60 \\
Vm [V] & 31.5 & 26.3 & 17.1 \\
Im [A] & 8.89 & 7.61 & 3.5 \\
Vo [V] & 38.5 & 32.9 & 21.1 \\
Isc [A] & 9.43 & 8.21 & 3.8 \\
$\mathrm{Ns}[$ cells] & 60 & 54 & 36 \\
$\mathrm{Ki}$ & $0.053 \% /{ }^{\circ} \mathrm{C}$ & $0.00318 \mathrm{~A} /{ }^{\circ} \mathrm{C}$ & $0.065 \% /{ }^{\circ} \mathrm{C}$ \\
$\mathrm{Kv}$ & $-0.31 \% /{ }^{\circ} \mathrm{C}$ & $-0.123 \mathrm{~V} /{ }^{\circ} \mathrm{C}$ & $-0.08 \mathrm{~V} /{ }^{\circ} \mathrm{C}$ \\
\hline
\end{tabular}


The proposed chaotic version of chicken swarm optimization (CCSO) is executed to minimize the objective function stated in Eq. (22). The no. of search agents considered for the experiments is 50 and the maximum iteration is taken as 1000 for all the algorithms. The results of the proposed heuristic algorithm are compared with the other algorithms which are briefed below for the inquisitive readers.

The Dragonfly Algorithm (DA) is a swarm intelligence algorithm inspired by the social interaction of dragonflies in navigating, seeking food and avoiding opponents whether swarming dynamically or statistically [45]. Ant Lion Optimizer (ALO) is motivated by the hunting technique of antlions for food search in nature [46]. Multi-Verse Optimizer (MVO) considers the three basic concepts of cosmology namely black hole, white hole and wormhole [47]. Whale Optimization Algorithm (WOA), a nature-inspired meta-heuristic optimization algorithm replicates the social behaviour of humpback whales. The bubble-net hunting approach is usually followed in this algorithm [48]. Grasshopper Optimization Algorithm (GOA) is a swarm inspired algorithm that aims at imitating the behaviour of the swarms of grasshoppers [49]. Sine Cosine Algorithm (SCA) is another population-based optimization algorithm that is inspired by sine and cosine mathematical functions. The SCA generates numerous initial random candidate solutions and fluctuates them outwards or towards to obtain the optimal solution [50]. Salp Swarm Algorithm (SSA) is a swarm-based optimization technique inspired by the swarming behaviour of salps while foraging and navigating in the water bodies [23]. Harris Hawks Optimization (HHO) is also a naturedependent algorithm. The cooperative behaviour and pursuit manner of Harris' hawks in nature, known as surprise pounce, is the fundamental inspiration for this technique [51]. Atom Search Optimization (ASO) is yet another population-based iterative heuristic global optimization algorithm. ASO imitates the motion of the atomic model in nature, where atoms interact with each other through interaction forces resulting from Lennard-Jones potential and constraint forces resulting from bond-length potential [52]. Apart from these algorithms, the proposed methods are also compared with two existing chaotic versions of the chicken swarm modified by logistic [43] and tent [44] maps. The logistic map motivated CSO is referred to as CCSO_1 in this work. Similarly, CCSO_2 is the tent map oriented chicken swarm method reported in this paper.

The electrical parameters of the TDM are evaluated with the proposed method as well as the algorithms meant for comparison. The metaheuristic approaches used to obtain the parameters are stochastic i.e. their outcomes change on every test run. Hence, there is the 
requirement of finding some popular statistical measures of the error function for a set of independent test runs. Thus, 30 test runs are carried out to get meaningful statistical measures. The minimum and the maximum value as the average and the standard deviation of the error functions are thus recorded. Besides, non-parametric tests (Wilcoxon rank-sum test, Kruskal-Wallis test, Wilcoxon rank test with Holm-Bonferroni correction) are also performed to certify the significances of the obtained results. The results of the test models considered in this work are thus discussed below.

Case 1: In this case Canadian solar (CS6K 280M mono-crystalline) commercial module is examined. All the earlier mentioned algorithms are executed to extract all the nine parameters of the TDM. Table 3 describes the extracted parameters of the TDM.

Table 3. Parameter estimation of TDM for Canadian solar (CS6K 280M mono-crystalline)

\begin{tabular}{|c|c|c|c|c|c|c|c|c|c|}
\hline Methods & $\mathrm{I}_{\mathrm{PV}}$ & $\alpha_{1}$ & $\alpha_{2}$ & $\alpha_{3}$ & $\mathrm{R}_{\mathrm{S}}$ & $\mathrm{R}_{\mathrm{sh}}$ & $\mathrm{I}_{01}$ & $\mathrm{I}_{02}$ & $\mathrm{I}_{03}$ \\
\hline CCSO (Circle) & 9.4302 & 1.6884 & 1.7412 & 1.8431 & 0.0081 & 456.1701 & $3.3946 \mathrm{e}-07$ & $4.3468 \mathrm{e}-07$ & $3.1319 \mathrm{e}-07$ \\
\hline CCSO (Iterative) & 9.4302 & 1.6470 & 1.6948 & 1.8248 & 0.0099 & 446.8661 & $2.8017 \mathrm{e}-07$ & $3.2204 \mathrm{e}-07$ & $3.6688 \mathrm{e}-07$ \\
\hline CCSO (Logistic) & 9.4302 & 1.7011 & 1.7236 & 1.7694 & 0.0066 & 432.5930 & $3.2903 \mathrm{e}-07$ & $3.9987 \mathrm{e}-07$ & $3.3506 \mathrm{e}-07$ \\
\hline CCSO (Piecewise) & 9.4302 & 1.6996 & 1.6713 & 1.8001 & 0.0081 & 417.9113 & $2.8271 \mathrm{e}-07$ & $3.7024 \mathrm{e}-07$ & $4.5862 \mathrm{e}-07$ \\
\hline CCSO (Sinusoidal) & 9.4302 & 1.7406 & 1.6909 & 1.7957 & 0.0117 & 441.2769 & $2.8295 \mathrm{e}-07$ & $3.7913 \mathrm{e}-07$ & $4.6381 \mathrm{e}-07$ \\
\hline CCSO (Tent) & 9.4303 & 1.7344 & 1.6349 & 1.8037 & 0.0165 & 387.3281 & $2.4279 \mathrm{e}-07$ & $3.3020 \mathrm{e}-07$ & $3.0763 \mathrm{e}-07$ \\
\hline CSO [37] & 9.4376 & 1.6469 & 1.8064 & 1.6449 & 0.0139 & 432.4226 & $3.9518 \mathrm{e}-07$ & $5.9630 \mathrm{e}-07$ & $3.3322 \mathrm{e}-07$ \\
\hline CCSO_1 [43] & 9.5919 & 1.6783 & 1.5793 & 1.6907 & 0.0114 & 168.4052 & $3.2497 \mathrm{e}-07$ & $1.0000 \mathrm{e}-06$ & $3.7308 \mathrm{e}-07$ \\
\hline CCSO_2 [44] & 9.5001 & 1.7456 & 1.5987 & 1.6243 & 0.0064 & 405.1702 & $2.5391 \mathrm{e}-13$ & $8.8031 \mathrm{e}-07$ & $8.3465 \mathrm{e}-07$ \\
\hline GOA [49] & 9.6851 & 1.7206 & 1.6887 & 1.7157 & 0.2185 & 489.0740 & $3.8567 \mathrm{e}-07$ & $3.6657 \mathrm{e}-07$ & $4.5994 \mathrm{e}-07$ \\
\hline HHO [51] & 9.7083 & 1.6468 & 1.7031 & 1.6678 & 0.2661 & 315.3751 & $5.5896 \mathrm{e}-07$ & $5.6685 \mathrm{e}-07$ & $5.4425 \mathrm{e}-07$ \\
\hline SCA [50] & 9.4827 & 1.2621 & 1.2784 & 1.1406 & 0.0184 & 318.5973 & $1.5203 \mathrm{e}-07$ & $2.1090 \mathrm{e}-07$ & $1.6321 \mathrm{e}-07$ \\
\hline SSA [23] & 9.5144 & 1.5928 & 1.6413 & 1.6907 & 0.0678 & 299.7689 & $4.3274 \mathrm{e}-07$ & $4.6313 \mathrm{e}-07$ & $4.7420 \mathrm{e}-07$ \\
\hline ASO [52] & 9.4309 & 1.6649 & 1.6284 & 1.6768 & 0.0161 & 318.0123 & $3.4217 \mathrm{e}-07$ & $4.4015 \mathrm{e}-07$ & $3.4157 \mathrm{e}-07$ \\
\hline
\end{tabular}

Table 4 shows the normalized value of parameters (minimum, maximum, mean, and standard deviation) of SSE and eq. (30) presents the formula for normalization of the result value. The normalized values lie between 0 and 1 , where 0 refers to the least value and 1 represents the worst value. From the result, it is evident that the CCSO algorithm parameters of SSE achieve the least value for the PV model in comparison with other algorithms. 
Table 4. Normalized results of the SSE for TDM for Canadian solar (CS6K 280M monocrystalline)

\begin{tabular}{|c|c|c|c|c|}
\hline Algorithms & Min & Max & Mean & $\begin{array}{l}\text { Standard } \\
\text { Deviation }\end{array}$ \\
\hline CCSO (Chebyshev) & $3.7837 \mathrm{e}-10$ & $2.0923 \mathrm{e}-10$ & $9.9697 \mathrm{e}-10$ & $6.0289 \mathrm{e}-10$ \\
\hline CCSO (Circle) & $4.5385 \mathrm{e}-11$ & $8.0625 \mathrm{e}-11$ & $3.3914 \mathrm{e}-10$ & $3.8078 \mathrm{e}-10$ \\
\hline CCSO (Gauss) & $1.0529 \mathrm{e}-10$ & $1.5784 \mathrm{e}-11$ & $6.3807 \mathrm{e}-10$ & $4.9947 \mathrm{e}-10$ \\
\hline CCSO (Iterative) & $1.6923 \mathrm{e}-11$ & $2.1451 \mathrm{e}-10$ & $2.2199 \mathrm{e}-10$ & $\mathbf{0}$ \\
\hline CCSO (Logistic) & $4.4712 \mathrm{e}-10$ & $2.0400 \mathrm{e}-10$ & $3.9022 \mathrm{e}-10$ & $4.1044 \mathrm{e}-10$ \\
\hline CCSO (Piecewise) & $\mathbf{0}$ & $1.5586 \mathrm{e}-10$ & $4.6951 \mathrm{e}-10$ & $1.6368 \mathrm{e}-10$ \\
\hline CCSO (Sine) & $8.6154 \mathrm{e}-11$ & $1.6130 \mathrm{e}-10$ & $3.6962 \mathrm{e}-10$ & $4.4092 \mathrm{e}-10$ \\
\hline CCSO (Singer) & $7.1827 \mathrm{e}-11$ & $2.7962 \mathrm{e}-10$ & $3.2825 \mathrm{e}-10$ & $5.3302 \mathrm{e}-10$ \\
\hline CCSO (Sinusoidal) & $1.9567 \mathrm{e}-10$ & $1.0273 \mathrm{e}-10$ & $4.5692 \mathrm{e}-10$ & $4.2983 \mathrm{e}-10$ \\
\hline CCSO (Tent) & $1.4808 \mathrm{e}-11$ & $\mathbf{0}$ & $\mathbf{0}$ & $2.6274 \mathrm{e}-10$ \\
\hline CCSO_1 [43] & $9.6051 \mathrm{e}-08$ & $1.6305 \mathrm{e}-07$ & $3.7091 \mathrm{e}-08$ & $5.8442 \mathrm{e}-08$ \\
\hline CCSO_2 [44] & $9.7515 \mathrm{e}-08$ & $1.3148 \mathrm{e}-07$ & $1.1080 \mathrm{e}-07$ & $1.0855 \mathrm{e}-07$ \\
\hline $\mathrm{CSO}[\overline{3} 7]$ & $1.1575 \mathrm{e}-03$ & $1.5368 \mathrm{e}-03$ & $1.4558 \mathrm{e}-03$ & $1.6350 \mathrm{e}-03$ \\
\hline DA [45] & $1.0000 \mathrm{e}+00$ & $6.7505 \mathrm{e}-01$ & $9.5980 \mathrm{e}-01$ & $5.2476 \mathrm{e}-01$ \\
\hline ALO [46] & $1.1538 \mathrm{e}-02$ & $1.5718 \mathrm{e}-02$ & $1.7065 \mathrm{e}-02$ & $1.3561 \mathrm{e}-02$ \\
\hline MVO [47] & $9.6154 \mathrm{e}-03$ & $1.5884 \mathrm{e}-02$ & $1.5169 \mathrm{e}-02$ & $1.5330 \mathrm{e}-02$ \\
\hline WOA [48] & $1.0769 \mathrm{e}-01$ & $1.5751 \mathrm{e}-01$ & $1.5055 \mathrm{e}-01$ & $1.5212 \mathrm{e}-01$ \\
\hline GOA [49] & $2.2212 \mathrm{e}-01$ & $1.5470 \mathrm{e}-01$ & $1.8999 \mathrm{e}-01$ & $1.1733 \mathrm{e}-01$ \\
\hline SCA [50] & $9.8077 \mathrm{e}-02$ & $1.4246 \mathrm{e}-01$ & $1.1642 \mathrm{e}-01$ & $1.0083 \mathrm{e}-01$ \\
\hline SSA [23] & $1.0288 \mathrm{e}-01$ & $1.3302 \mathrm{e}-01$ & $1.2173 \mathrm{e}-01$ & $1.2323 \mathrm{e}-01$ \\
\hline HHO [51] & $9.6346 \mathrm{e}-01$ & $1.0000 \mathrm{e}+00$ & $1.0000 \mathrm{e}+00$ & $1.0000 \mathrm{e}+00$ \\
\hline ASO [52] & $9.6154 \mathrm{e}-03$ & $1.5884 \mathrm{e}-02$ & $2.1236 \mathrm{e}-02$ & $1.6509 \mathrm{e}-02$ \\
\hline
\end{tabular}

As observed in Table 4, the proposed method outperforms the existing algorithms. The best results in each column are indicated using bold letters. Moreover, the convergences curve of the TDM is plotted to prove the significance of the extracted error value. Fig. 4 shows the list of convergences curve of each variant of CCSO with other compared algorithms (CCSO, DA, ALO, MVO, WOA, GOA, SCA, SSA, HHO, ASO).

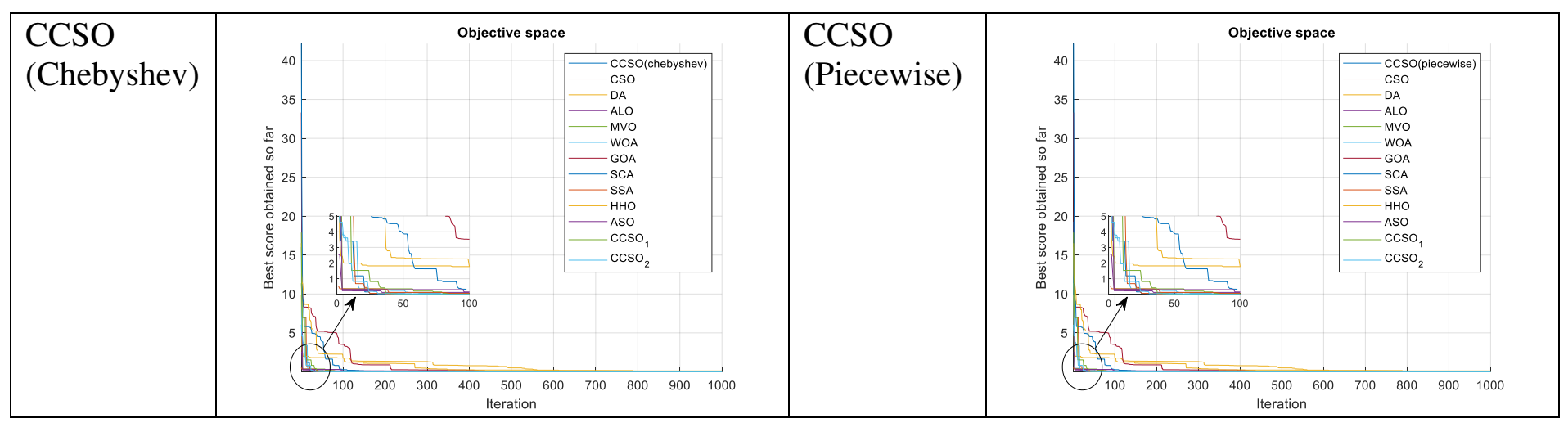




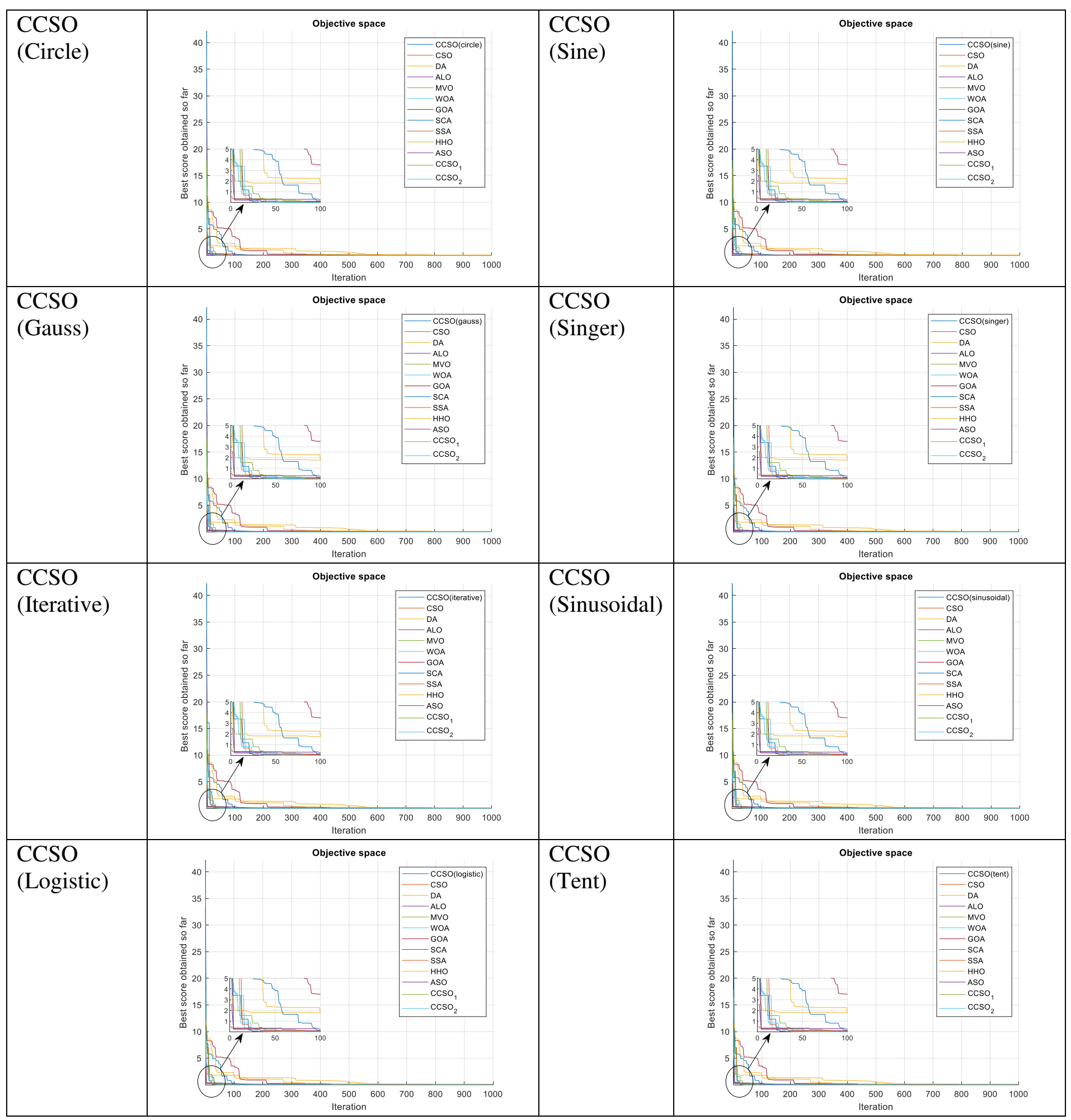

Fig. 5. Convergences curves of the proposed methods.

The plot in Fig. 5. clearly shows that the proposed methods supersede the algorithms used for comparison. Fig. 6. showcases the I-V curves of all variants of CCSO. The resultant curves resemble the standard I-V curve of the solar model proving the accuracy of the proposed techniques. 


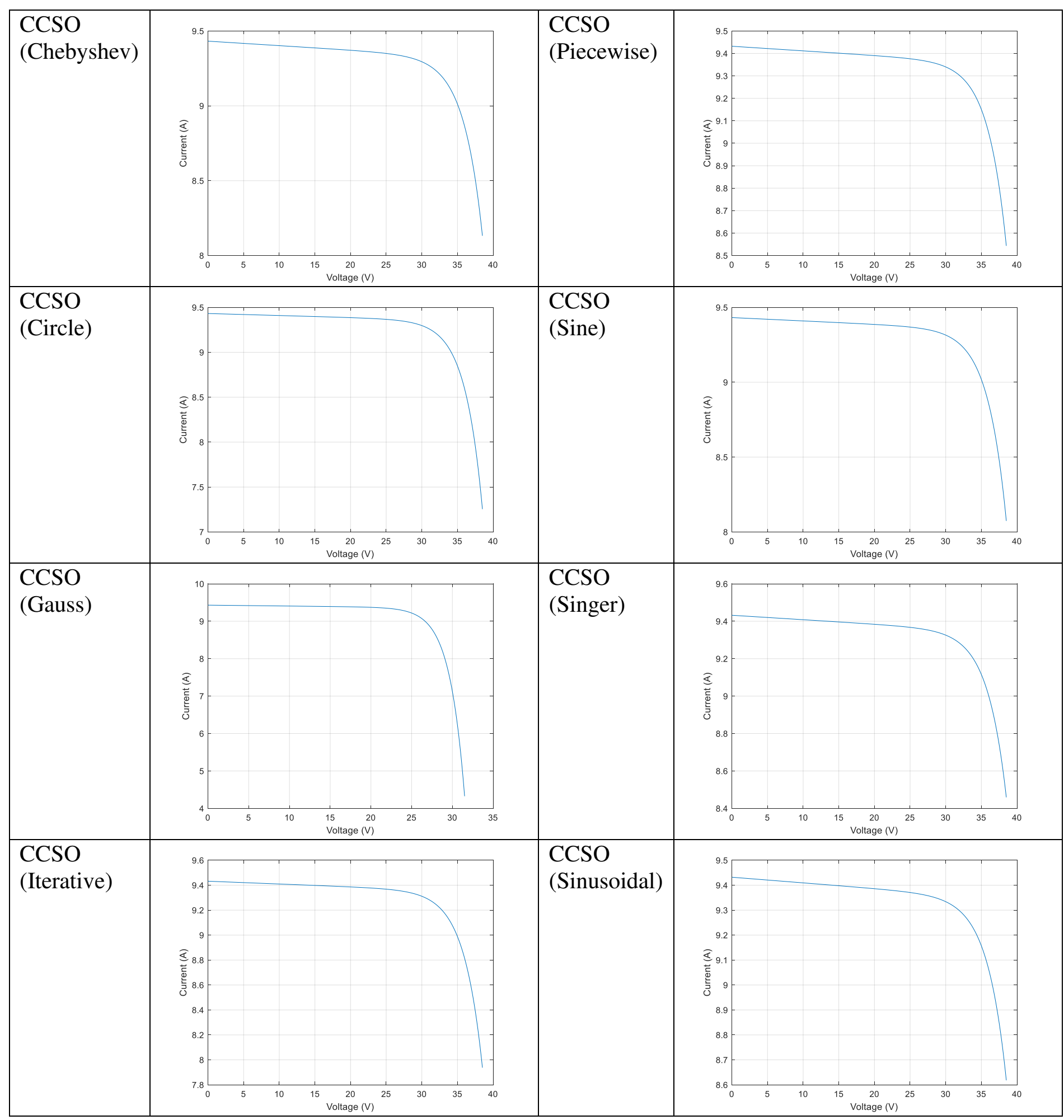




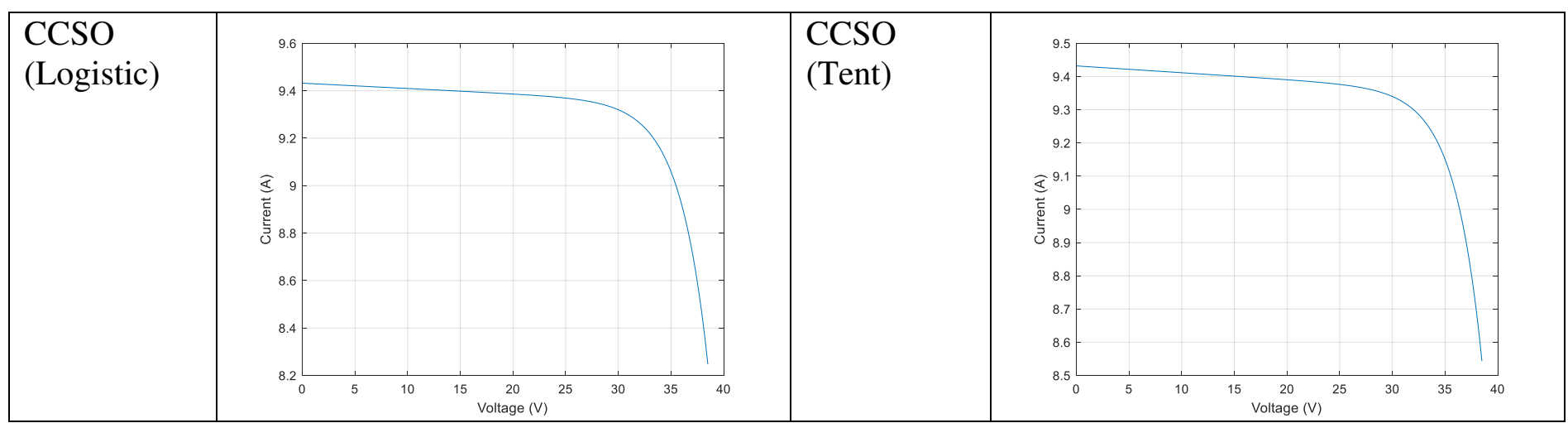

Fig. 6. I-V curves of the proposed CCSO technique.

On a similar note, Fig. 7. shows the P-V curves of all variants of CCSO. The curves look very much similar to the standard P-V curve of the solar model proving the accuracy of the proposed approaches.

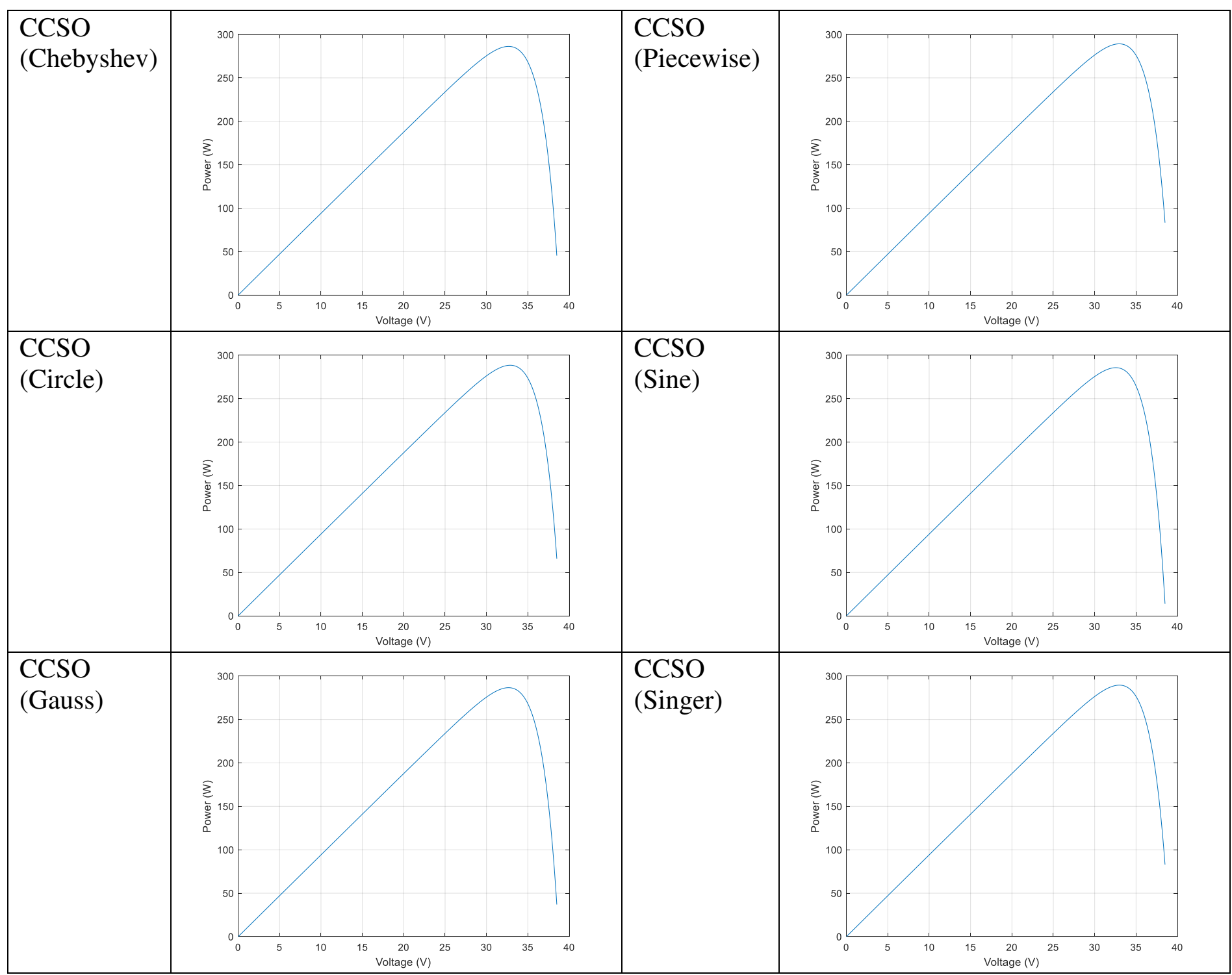




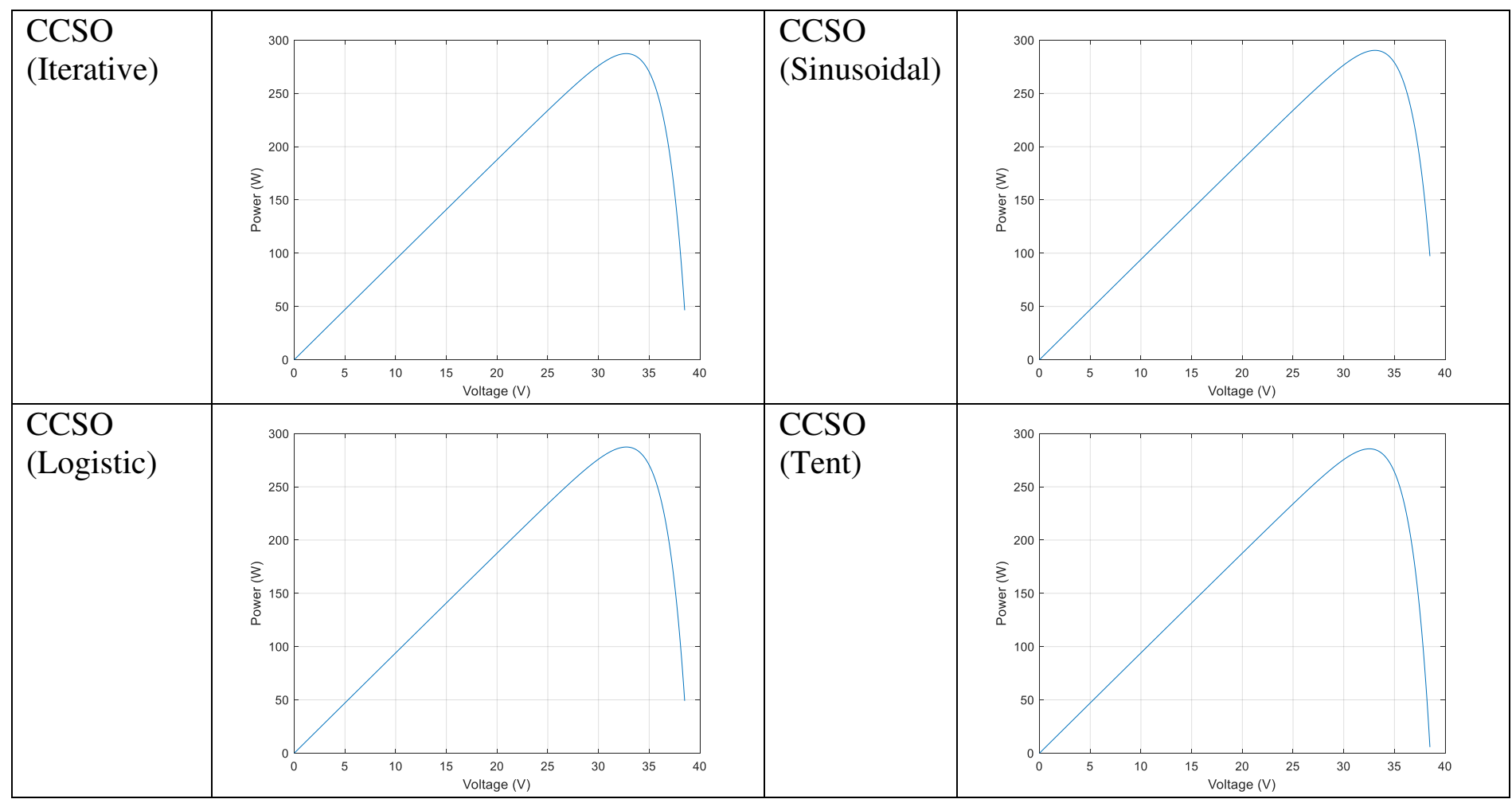

Fig. 7. P-V curves of all variants of CCSO.

For better validation of the results, non-parametric tests are conducted. Initially, the rank-sum test of Wilcoxon [30] is carried out. Table 5(a) and 5(b) lists the calculated p-values and justifies that the performances of all variants of CCSO are significant, considering a significance level of $95 \%$.

Table 5(a). p-values for the Wilcoxon rank-sum test.

\begin{tabular}{|c|c|c|c|c|c|c|}
\hline Algorithms & $\mathrm{CSO}$ & DA & ALO & MVO & WOA & GOA \\
\hline CCSO (Chebyshev) & $3.0253 \mathrm{e}-11$ & $3.0161 \mathrm{e}-11$ & $2.9947 \mathrm{e}-11$ & $3.0142 \mathrm{e}-11$ & $3.0180 \mathrm{e}-11$ & $2.9921 \mathrm{e}-11$ \\
\hline CCSO (Circle) & $3.0467 \mathrm{e}-11$ & $2.9770 \mathrm{e}-11$ & $3.0259 \mathrm{e}-11$ & $3.0021 \mathrm{e}-11$ & $2.9966 \mathrm{e}-11$ & $2.9175 \mathrm{e}-11$ \\
\hline CCSO (Gauss) & $3.0148 \mathrm{e}-11$ & $3.0516 \mathrm{e}-11$ & $3.0422 \mathrm{e}-11$ & $3.0570 \mathrm{e}-11$ & $3.0719 \mathrm{e}-11$ & $2.9564 \mathrm{e}-11$ \\
\hline CCSO (Iterative) & $3.0856 \mathrm{e}-11$ & $3.0187 \mathrm{e}-11$ & $3.0905 \mathrm{e}-11$ & $3.0164 \mathrm{e}-11$ & $3.0804 \mathrm{e}-11$ & $2.9991 \mathrm{e}-11$ \\
\hline CCSO (Logistic) & $3.0910 \mathrm{e}-11$ & $3.0850 \mathrm{e}-11$ & $3.0611 \mathrm{e}-11$ & $3.0349 \mathrm{e}-11$ & $3.0133 \mathrm{e}-11$ & $3.0042 \mathrm{e}-11$ \\
\hline CCSO (Piecewise) & $3.0619 \mathrm{e}-11$ & $3.0912 \mathrm{e}-11$ & $3.0388 \mathrm{e}-11$ & $3.0949 \mathrm{e}-11$ & $3.0481 \mathrm{e}-11$ & $2.9709 \mathrm{e}-11$ \\
\hline CCSO (Sine) & $3.0321 \mathrm{e}-11$ & $2.9428 \mathrm{e}-11$ & $3.0815 \mathrm{e}-11$ & $3.0073 \mathrm{e}-11$ & $3.0349 \mathrm{e}-11$ & $2.9613 \mathrm{e}-11$ \\
\hline WCCSO (Singer) & $3.0437 \mathrm{e}-11$ & $3.0666 \mathrm{e}-11$ & $3.0803 e-11$ & $3.0121 \mathrm{e}-11$ & $3.0091 \mathrm{e}-11$ & $2.9381 \mathrm{e}-11$ \\
\hline CCSO (Sinusoidal) & $3.0705 \mathrm{e}-11$ & $3.0009 \mathrm{e}-11$ & $3.0052 \mathrm{e}-11$ & $3.1017 \mathrm{e}-11$ & $2.9914 \mathrm{e}-11$ & $2.9850 \mathrm{e}-11$ \\
\hline CCSO (Tent) & $3.0193 \mathrm{e}-11$ & $3.0061 \mathrm{e}-11$ & $2.9969 \mathrm{e}-11$ & $3.0501 \mathrm{e}-11$ & $3.0801 \mathrm{e}-11$ & $3.0127 \mathrm{e}-11$ \\
\hline
\end{tabular}

Table 5(b). p-values for the Wilcoxon rank-sum test.

\begin{tabular}{lllllll}
\hline Algorithms & SCA & SSA & HHO & ASO & CCSO_1 & CCSO_2 \\
\hline CCSO (Chebyshev) & $3.0999 \mathrm{e}-11$ & $3.0104 \mathrm{e}-11$ & $3.0617 \mathrm{e}-11$ & $2.9957 \mathrm{e}-11$ & $2.9878 \mathrm{e}-11$ & $2.9860 \mathrm{e}-11$ \\
CCSO (Circle) & $3.0123 \mathrm{e}-11$ & $3.0597 \mathrm{e}-11$ & $3.0102 \mathrm{e}-11$ & $2.9891 \mathrm{e}-11$ & $3.0085 \mathrm{e}-11$ & $3.0066 \mathrm{e}-11$ \\
CCSO (Gauss) & $3.0357 \mathrm{e}-11$ & $3.0091 \mathrm{e}-11$ & $3.0199 \mathrm{e}-11$ & $2.9530 \mathrm{e}-11$ & $2.9935 \mathrm{e}-11$ & $2.9916 \mathrm{e}-11$ \\
CCSO (Iterative) & $3.0638 \mathrm{e}-11$ & $2.9964 \mathrm{e}-11$ & $2.9983 \mathrm{e}-11$ & $2.9204 \mathrm{e}-11$ & $3.0066 \mathrm{e}-11$ & $3.0047 \mathrm{e}-11$ \\
CCSO (Logistic) & $3.0529 \mathrm{e}-11$ & $3.0137 \mathrm{e}-11$ & $3.0544 \mathrm{e}-11$ & $2.9384 \mathrm{e}-11$ & $2.9916 \mathrm{e}-11$ & $3.0142 \mathrm{e}-11$ \\
CCSO (Piecewise) & $3.0246 \mathrm{e}-11$ & $3.0339 \mathrm{e}-11$ & $3.0489 \mathrm{e}-11$ & $2.9901 \mathrm{e}-11$ & $3.0123 \mathrm{e}-11$ & $3.0010 \mathrm{e}-11$ \\
CCSO (Sine) & $3.0814 \mathrm{e}-11$ & $3.0815 \mathrm{e}-11$ & $3.0261 \mathrm{e}-11$ & $2.9407 \mathrm{e}-11$ & $2.9991 \mathrm{e}-11$ & $3.0010 \mathrm{e}-11$ \\
WCCSO (Singer) & $3.0551 \mathrm{e}-11$ & $3.0740 \mathrm{e}-11$ & $3.0115 \mathrm{e}-11$ & $2.9755 \mathrm{e}-11$ & $3.0010 \mathrm{e}-11$ & $2.9991 \mathrm{e}-11$ \\
CCSO (Sinusoidal) & $3.0349 \mathrm{e}-11$ & $3.0442 \mathrm{e}-11$ & $3.0591 \mathrm{e}-11$ & $2.9102 \mathrm{e}-11$ & $2.9991 \mathrm{e}-11$ & $2.9972 \mathrm{e}-11$ \\
CCSO (Tent) & $3.0100 \mathrm{e}-11$ & $3.1145 \mathrm{e}-11$ & $3.0102 \mathrm{e}-11$ & $2.9991 \mathrm{e}-11$ & $3.0066 \mathrm{e}-11$ & $3.0047 \mathrm{e}-11$ \\
\hline
\end{tabular}


The next non-parametric test taken up for the investigation is the Kruskal Wallis test [31], which signify the difference between the mean ranks obtained by the various techniques. The outcome graphs presented in Fig. 8. shows that the mean ranks of the CCSO techniques are significantly different from the other algorithms.

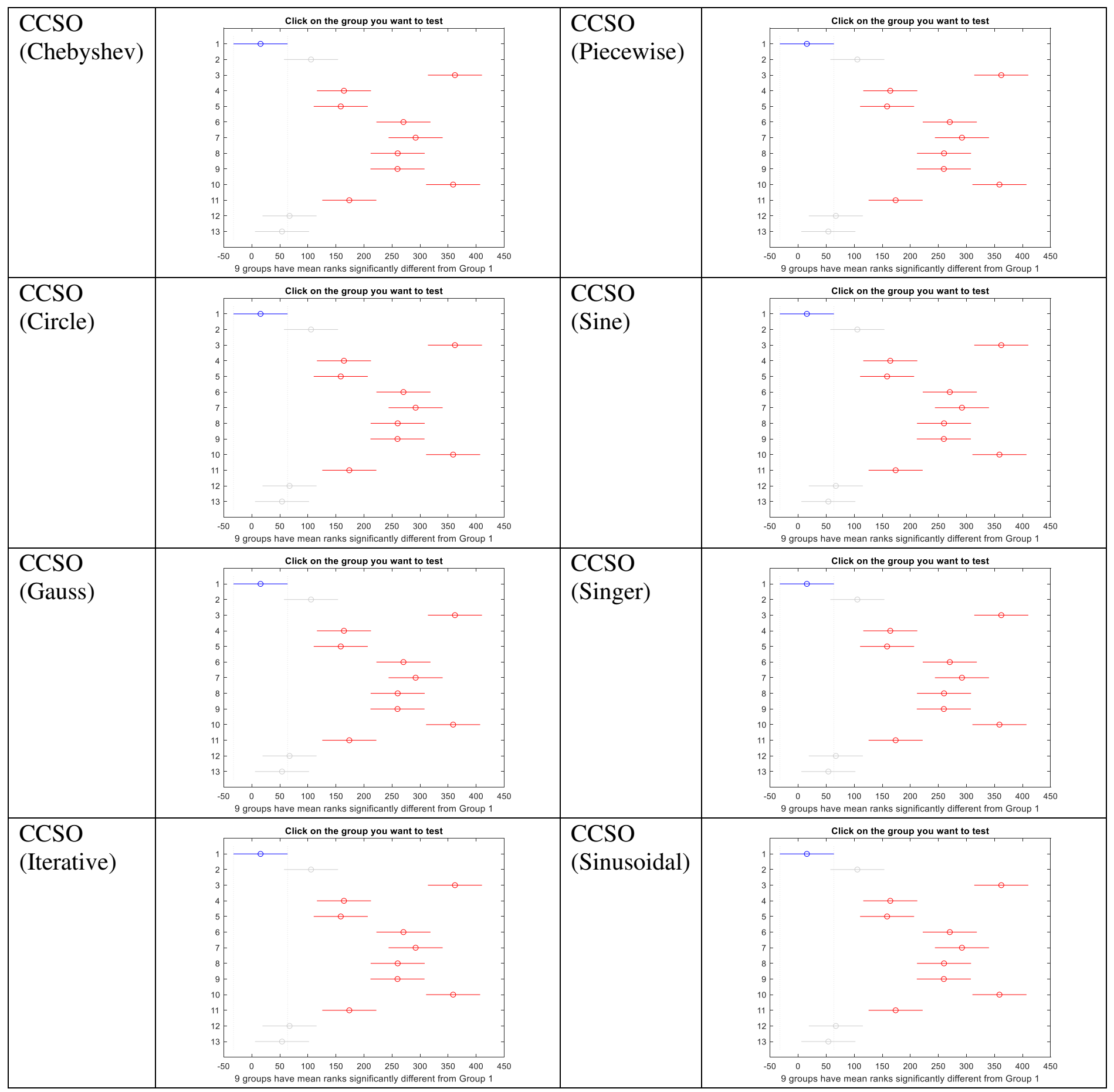




\begin{tabular}{|l|l|l|l|l|l|l|}
\hline CCSO \\
(Logistic)
\end{tabular}

Fig. 8. Kruskal Wallis test diagram for the Canadian solar (CS6K 280M mono-crystalline) model results.

At last, p-values obtained by the Wilcoxon rank test is assessed applying the HolmBonferroni corrections [32] method and the outcome of the experiment are presented in Table 6(a) and 6(b).

Table 6(a). Corrected p-values by Holm-Bonferroni corrections for Wilcoxon rank test.

(Multiply the results with (1.0e-09) and test of significance (h) is 1)

\begin{tabular}{llllllc}
\hline Algorithms & CSO & DA & ALO & MVO & WOA & GOA \\
\hline CCSO (Chebyshev) & 0.2930 & 0.0894 & 0.1785 & 0.1488 & 0.2077 & 0.2930 \\
CCSO (Circle) & 0.2651 & 0.0900 & 0.1797 & 0.1499 & 0.2091 & 0.2951 \\
CCSO (Gauss) & 0.2936 & 0.0896 & 0.1788 & 0.2081 & 0.1491 & 0.2936 \\
CCSO (Iterative) & 0.2949 & 0.0900 & 0.1796 & 0.1498 & 0.2090 & 0.2946 \\
CCSO (Logistic) & 0.2962 & 0.0904 & 0.1804 & 0.1504 & 0.2099 & 0.2962 \\
CCSO (Piecewise) & 0.2956 & 0.0902 & 0.1801 & 0.1501 & 0.2095 & 0.2956 \\
CCSO (Sine) & 0.2643 & 0.0898 & 0.1793 & 0.1495 & 0.2086 & 0.2943 \\
CCSO (Singer) & 0.2643 & 0.0898 & 0.1793 & 0.1495 & 0.2086 & 0.2943 \\
CCSO (Sinusoidal) & 0.2941 & 0.0897 & 0.1792 & 0.1494 & 0.2085 & 0.2941 \\
CCSO (Tent) & 0.2906 & 0.0903 & 0.1803 & 0.1503 & 0.209 & 0.2960 \\
\hline
\end{tabular}

Table 6(b). Corrected p-values by Holm-Bonferroni corrections for Wilcoxon rank test.

(Multiply the results with (1.0e-09) and test of significance (h) is 1)

\begin{tabular}{lllllll}
\hline Algorithms & SCA & SSA & HHO & ASO & CCSO_1 & CCSO_2 \\
\hline CCSO (Chebyshev) & 0.0597 & 0.2371 & 0.2666 & 0.1191 & 0.0597 & 0.0896 \\
CCSO (Circle) & 0.0601 & 0.2387 & 0.2684 & 0.1200 & 0.0601 & 0.0902 \\
CCSO (Gauss) & 0.0598 & 0.2375 & 0.2671 & 0.1194 & 0.0598 & 0.0897 \\
CCSO (Iterative) & 0.0601 & 0.2386 & 0.2682 & 0.1199 & 0.0601 & 0.0901 \\
CCSO (Logistic) & 0.0604 & 0.2396 & 0.2694 & 0.1204 & 0.3554 & 0.1205 \\
CCSO (Piecewise) & 0.0602 & 0.2396 & 0.2689 & 0.1202 & 0.0602 & 0.2401 \\
CCSO (Sine) & 0.0600 & 0.2381 & 0.2677 & 0.1197 & 0.0600 & 0.1497 \\
CCSO (Singer) & 0.0600 & 0.2381 & 0.2677 & 0.1197 & 0.0600 & 0.2093 \\
CCSO (Sinusoidal) & 0.0599 & 0.2380 & 0.2676 & 0.1196 & 0.0599 & 0.0899 \\
CCSO (Tent) & 0.0603 & 0.2395 & 0.2692 & 0.1203 & 0.2103 & 0.2404 \\
\hline
\end{tabular}

Case 2: In this case, Kyocera (KC200GT multi-crystal) commercial module is investigated. Similar to case 1, all the earlier mentioned algorithms are executed to extract the nine parameters of the TDM. Table 7. narrates the extracted parameters of the model. 
Table 7. Parameter estimation of TDM for Kyocera (KC200GT multi-crystal).

\begin{tabular}{|c|c|c|c|c|c|c|c|c|c|}
\hline Methods & $\mathrm{I}_{\mathrm{PV}}$ & $\alpha_{1}$ & $\alpha_{2}$ & $\alpha_{3}$ & $\mathrm{R}_{\mathrm{S}}$ & $\mathrm{R}_{\mathrm{sh}}$ & $\mathrm{I}_{01}$ & $\mathrm{I}_{02}$ & $\mathrm{I}_{03}$ \\
\hline CCSO (Chebyshev) & 8.2130 & 1.6658 & 1.6556 & 1.7091 & 0.1193 & 333.9284 & $5.3308 \mathrm{e}-07$ & $5.3267 \mathrm{e}-07$ & $4.9854 \mathrm{e}-07$ \\
\hline CCSO (Circle) & 8.2129 & 1.6706 & 1.7231 & 1.7735 & 0.1141 & 312.5405 & $5.5423 \mathrm{e}-07$ & $5.1728 \mathrm{e}-07$ & $4.6744 \mathrm{e}-07$ \\
\hline CCSO (Gauss) & 8.2131 & 1.7841 & 1.7700 & 1.6347 & 0.1111 & 292.0575 & $4.7194 \mathrm{e}-07$ & $5.2759 \mathrm{e}-07$ & $5.4345 \mathrm{e}-07$ \\
\hline CCSO (Iterative) & 8.2131 & 1.6090 & 1.6955 & 1.7410 & 0.1165 & 327.0842 & $5.5305 \mathrm{e}-07$ & $5.3586 \mathrm{e}-07$ & $5.3085 \mathrm{e}-07$ \\
\hline CCSO (Logistic) & 8.2131 & 1.6501 & 1.6966 & 1.7350 & 0.1146 & 312.4069 & $6.0508 \mathrm{e}-07$ & $5.2196 \mathrm{e}-07$ & $4.3595 \mathrm{e}-07$ \\
\hline CCSO (Piecewise) & 8.2132 & 1.6954 & 1.7424 & 1.6898 & 0.1211 & 326.4518 & $4.7269 \mathrm{e}-07$ & $4.0068 \mathrm{e}-07$ & $6.0666 \mathrm{e}-07$ \\
\hline CCSO (Sine) & 8.2132 & 1.6566 & 1.6252 & 1.7703 & 0.1163 & 316.2376 & $5.1367 \mathrm{e}-07$ & $5.8212 \mathrm{e}-07$ & $5.9493 \mathrm{e}-07$ \\
\hline CCSO (Singer) & 8.2130 & 1.6705 & 1.6734 & 1.7443 & 0.1128 & 313.8558 & $5.3980 \mathrm{e}-07$ & $5.9118 \mathrm{e}-07$ & $4.4266 \mathrm{e}-07$ \\
\hline CCSO (Sinusoidal) & 8.2130 & 1.6653 & 1.7153 & 1.6945 & 0.1119 & 318.3009 & $5.3401 \mathrm{e}-07$ & $5.6077 \mathrm{e}-07$ & $4.5432 \mathrm{e}-07$ \\
\hline CCSO (Tent) & 8.2128 & 1.6742 & 1.6924 & 1.7763 & 0.1017 & 280.9835 & $5.7969 \mathrm{e}-07$ & $5.7292 \mathrm{e}-07$ & $5.0378 \mathrm{e}-07$ \\
\hline CSO [37] & 8.2313 & 1.6820 & 1.6859 & 1.6439 & 0.1085 & 306.7303 & $5.8186 \mathrm{e}-07$ & $5.0013 \mathrm{e}-07$ & $7.8819 \mathrm{e}-07$ \\
\hline CCSO_1 [43] & 9.2807 & 1.7803 & 1.4536 & 1.7845 & 0.0669 & 368.5680 & $1.3831 \mathrm{e}-12$ & $3.1353 \mathrm{e}-07$ & $6.9422 \mathrm{e}-07$ \\
\hline CCSO_2 [44] & 9.4822 & 1.6481 & 1.5267 & 1.8391 & 0.0158 & 261.5054 & $3.5495 \mathrm{e}-07$ & $6.2141 \mathrm{e}-07$ & $2.0766 \mathrm{e}-07$ \\
\hline DA [45] & 8.2834 & 1.6078 & 1.6021 & 1.6533 & 0.1645 & 268.5313 & $4.3267 e-07$ & $5.4950 \mathrm{e}-07$ & $4.7144 \mathrm{e}-07$ \\
\hline ALO [46] & 8.2211 & 1.6809 & 1.5518 & 1.6750 & 0.1306 & 300.8825 & $5.9102 \mathrm{e}-07$ & $4.5750 \mathrm{e}-07$ & $5.1987 \mathrm{e}-07$ \\
\hline MVO [47] & 8.2259 & 1.5584 & 1.4697 & 1.5597 & 0.0673 & 212.0287 & $4.4118 \mathrm{e}-07$ & $5.0000 \mathrm{e}-07$ & $4.7611 \mathrm{e}-07$ \\
\hline WOA [48] & 8.3314 & 1.6144 & 1.6184 & 1.6021 & 0.2084 & 305.1682 & $4.8250 \mathrm{e}-07$ & $5.1301 \mathrm{e}-07$ & $5.0974 \mathrm{e}-07$ \\
\hline GOA [49] & 8.4111 & 1.6294 & 1.6620 & 1.6589 & 0.2978 & 484.0321 & $4.2411 \mathrm{e}-07$ & $3.5080 \mathrm{e}-07$ & $4.5325 \mathrm{e}-07$ \\
\hline SCA [50] & 8.1399 & 1.2748 & 1.1221 & 1.2842 & 0.0300 & 247.9600 & $2.0469 \mathrm{e}-07$ & $1.2317 \mathrm{e}-07$ & $1.5188 \mathrm{e}-07$ \\
\hline SSA [23] & 8.2564 & 1.5924 & 1.6130 & 1.6547 & 0.1596 & 282.5653 & $4.5039 \mathrm{e}-07$ & $4.2179 \mathrm{e}-07$ & $4.5471 \mathrm{e}-07$ \\
\hline HHO [51] & 8.4194 & 1.6210 & 1.5955 & 1.5878 & 0.2598 & 293.7824 & $5.5016 \mathrm{e}-07$ & $5.2750 \mathrm{E}-07$ & $5.3370 \mathrm{e}-07$ \\
\hline ASO [52] & 8.0589 & 1.6176 & 1.6035 & 1.5932 & 0.0948 & 294.1035 & $4.7272 \mathrm{e}-07$ & $4.1356 \mathrm{e}-07$ & $5.6861 \mathrm{e}-07$ \\
\hline
\end{tabular}

Table 8 showcases the normalized value of parameters (minimum, maximum, mean, and standard deviation) of SSE, respectively. The range of normalized values lies between 0 and 1 , where 0 refers to the least value and 1 represents the worst value. From the result, it is evident that the CCSO algorithm parameters of SSE achieve the least value for the PV model in comparison with the other algorithms.

Table 8. Normalized statistical measures of the SSE for TDM utilizing Kyocera (KC200GT multi-crystal).

\begin{tabular}{|c|c|c|c|c|}
\hline Algorithms & Min & Max & Mean & $\begin{array}{l}\text { Standard } \\
\text { Deviation }\end{array}$ \\
\hline CCSO (Chebyshev) & $4.6349 \mathrm{e}-10$ & $9.1571 \mathrm{e}-09$ & $2.2534 \mathrm{e}-09$ & $4.8522 \mathrm{e}-09$ \\
\hline CCSO (Circle) & $\mathbf{0}$ & $1.8614 \mathrm{e}-09$ & $\mathbf{0}$ & $1.4582 \mathrm{e}-09$ \\
\hline CCSO (Gauss) & $1.2048 \mathrm{e}-09$ & $1.8269 \mathrm{e}-09$ & $3.4355 \mathrm{e}-09$ & $2.8940 \mathrm{e}-09$ \\
\hline CCSO (Iterative) & $1.4087 \mathrm{e}-09$ & $1.2550 \mathrm{e}-09$ & $9.3643 \mathrm{e}-10$ & $1.6220 \mathrm{e}-09$ \\
\hline CCSO (Logistic) & $3.9365 \mathrm{e}-10$ & $1.6434 \mathrm{e}-09$ & $1.1905 \mathrm{e}-09$ & $1.7399 \mathrm{e}-09$ \\
\hline CCSO (Piecewise) & $9.7063 \mathrm{e}-10$ & $1.4493 \mathrm{e}-09$ & $8.4299 \mathrm{e}-10$ & $9.1530 \mathrm{e}-10$ \\
\hline CCSO (Sine) & $8.0873 \mathrm{e}-10$ & $1.6934 \mathrm{e}-09$ & $1.9688 \mathrm{e}-09$ & $3.2791 \mathrm{e}-09$ \\
\hline CCSO (Singer) & $1.2937 \mathrm{e}-09$ & $\mathbf{0}$ & $6.2059 \mathrm{e}-10$ & $\mathbf{0}$ \\
\hline CCSO (Sinusoidal) & $2.5238 \mathrm{e}-10$ & $1.2298 \mathrm{e}-09$ & $1.1242 \mathrm{e}-09$ & $1.4019 \mathrm{e}-09$ \\
\hline CCSO (Tent) & $9.0476 \mathrm{e}-11$ & $1.1452 \mathrm{e}-09$ & $4.7511 \mathrm{e}-11$ & $1.4519 \mathrm{e}-09$ \\
\hline CCSO_1 [43] & $8.2958 \mathrm{E}-07$ & $1.0045 \mathrm{E}-06$ & 8.6893E-07 & $8.8150 \mathrm{E}-07$ \\
\hline CCSO_2 [44] & $8.0567 \mathrm{E}-07$ & $9.5464 \mathrm{E}-07$ & $8.4452 \mathrm{E}-07$ & $8.6510 \mathrm{E}-04$ \\
\hline $\mathrm{CSO}[\overline{3} 7]$ & $8.8127 \mathrm{e}-05$ & $9.6342 \mathrm{e}-05$ & $7.7940 \mathrm{e}-05$ & $1.0521 \mathrm{e}-04$ \\
\hline DA [45] & $1.0000 \mathrm{e}+00$ & $6.8983 \mathrm{e}-01$ & $8.6878 \mathrm{e}-01$ & $7.6119 \mathrm{e}-01$ \\
\hline ALO [46] & $8.7302 \mathrm{e}-02$ & $9.4398 \mathrm{e}-02$ & $7.9186 \mathrm{e}-02$ & $8.2090 \mathrm{e}-02$ \\
\hline MVO [47] & $7.9365 \mathrm{e}-02$ & $9.5436 \mathrm{e}-02$ & $8.8235 \mathrm{e}-02$ & $9.3284 \mathrm{e}-02$ \\
\hline WOA [48] & $8.0159 \mathrm{e}-01$ & $1.0000 \mathrm{e}+00$ & $9.4570 \mathrm{e}-01$ & $9.3657 \mathrm{e}-01$ \\
\hline GOA [49] & $8.4127 \mathrm{e}-01$ & $9.7095 \mathrm{e}-01$ & $8.8235 \mathrm{e}-01$ & $1.0000 \mathrm{e}+00$ \\
\hline
\end{tabular}




\begin{tabular}{lllll} 
SCA [50] & $8.0952 \mathrm{e}-01$ & $9.9793 \mathrm{e}-01$ & $1.0000 \mathrm{e}+00$ & $8.3209 \mathrm{e}-01$ \\
SSA [23] & $1.1111 \mathrm{e}-01$ & $1.0062 \mathrm{e}-01$ & $1.1312 \mathrm{e}-01$ & $9.3284 \mathrm{e}-02$ \\
HHO [51] & $8.8095 \mathrm{e}-01$ & $8.7241 \mathrm{e}-01$ & $9.9548 \mathrm{e}-01$ & $9.1045 \mathrm{e}-01$ \\
ASO [52] & $8.7302 \mathrm{e}-02$ & $9.2324 \mathrm{e}-02$ & $9.0498 \mathrm{e}-02$ & $8.2090 \mathrm{e}-02$ \\
\hline
\end{tabular}

The chaotic map influenced CSO techniques thus accomplish significantly better as compared to some of the latest heuristic methods as seen from the results of Table 8 . The best outcomes in each column are also marked in bold. Moreover, the convergences characteristics of the TDM are plotted to prove the significance of the extracted error value. The convergence curves are provided in Fig. 9.

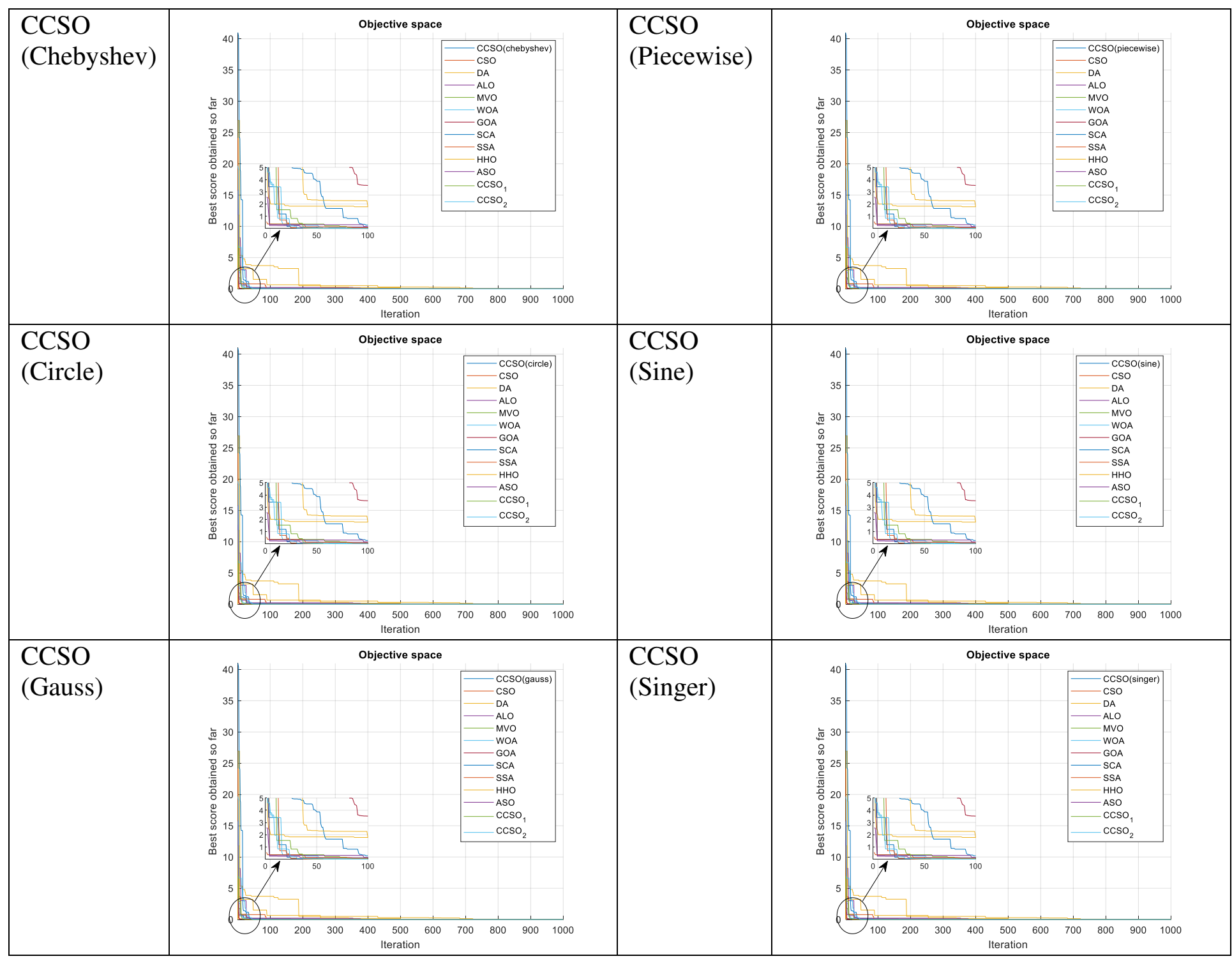




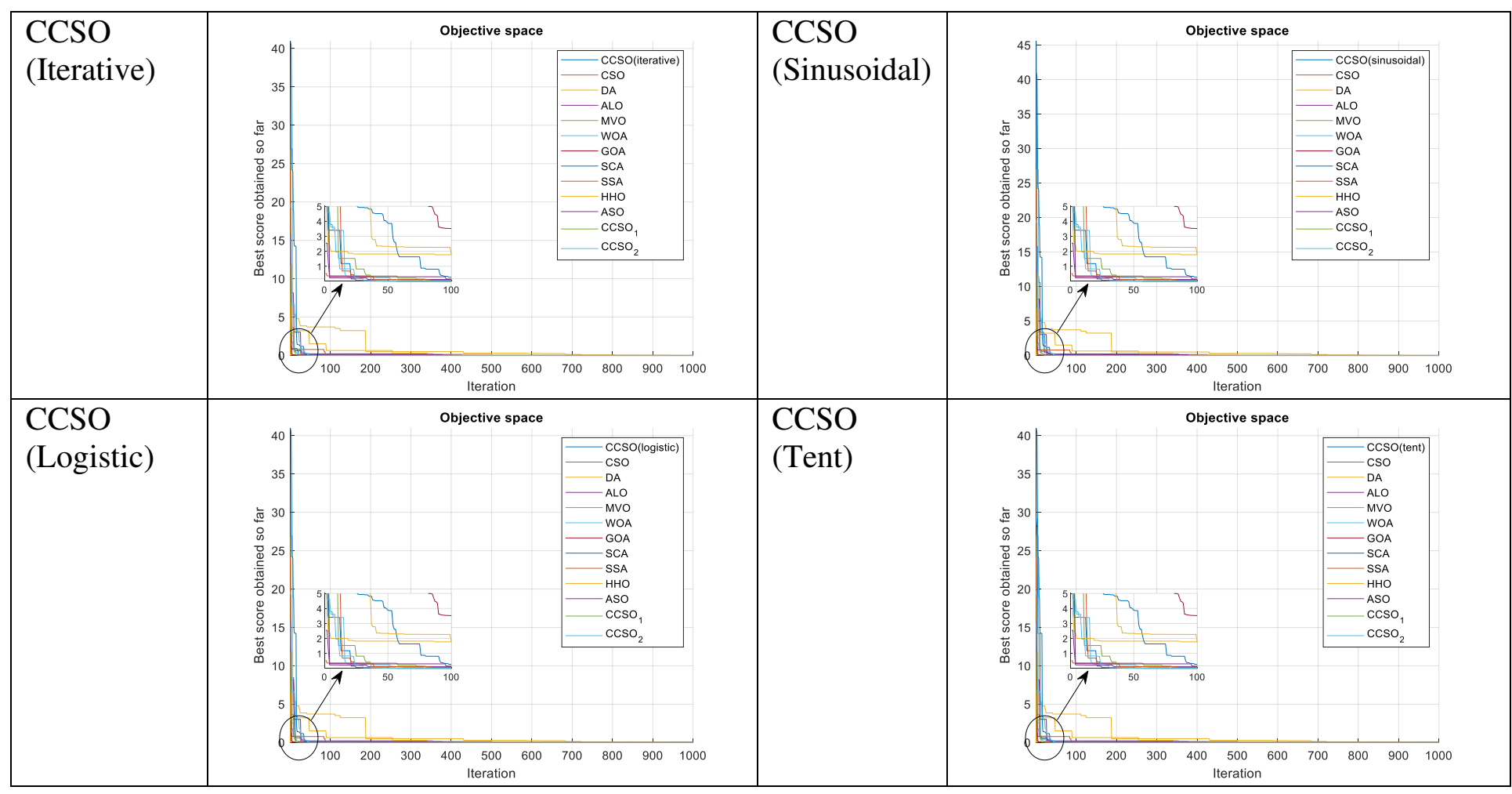

Fig. 9. Convergence plots of each variant of CCSO with other compared algorithms.

The proposed methods perform better in terms of convergence speed and accuracy as compared to the other algorithms. Fig. 10. Shows the I-V curves of all variants of CCSO. The curves are pretty similar to the ideal characteristic curves of the solar model proving the accuracy of the proposed methodology.

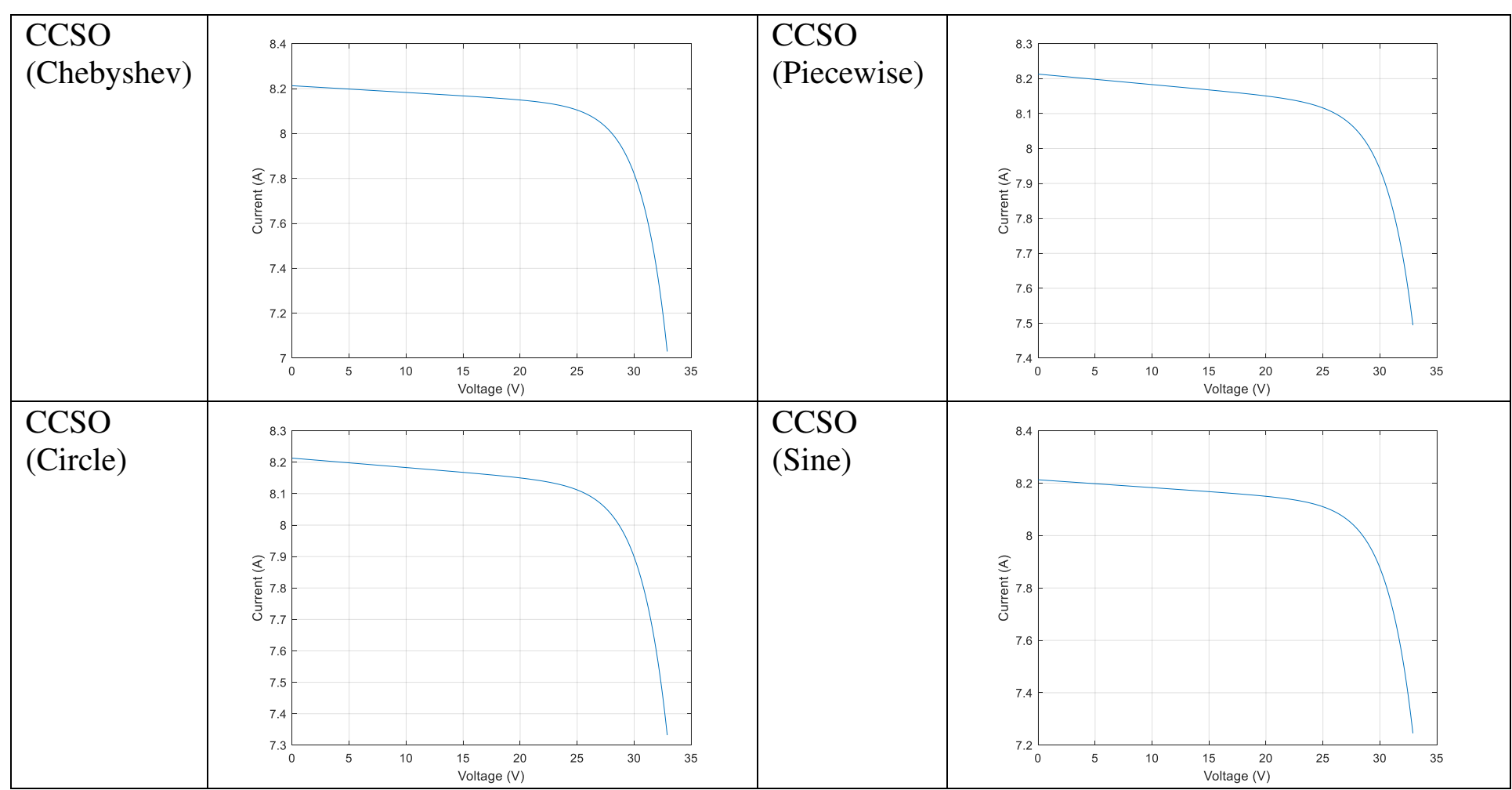




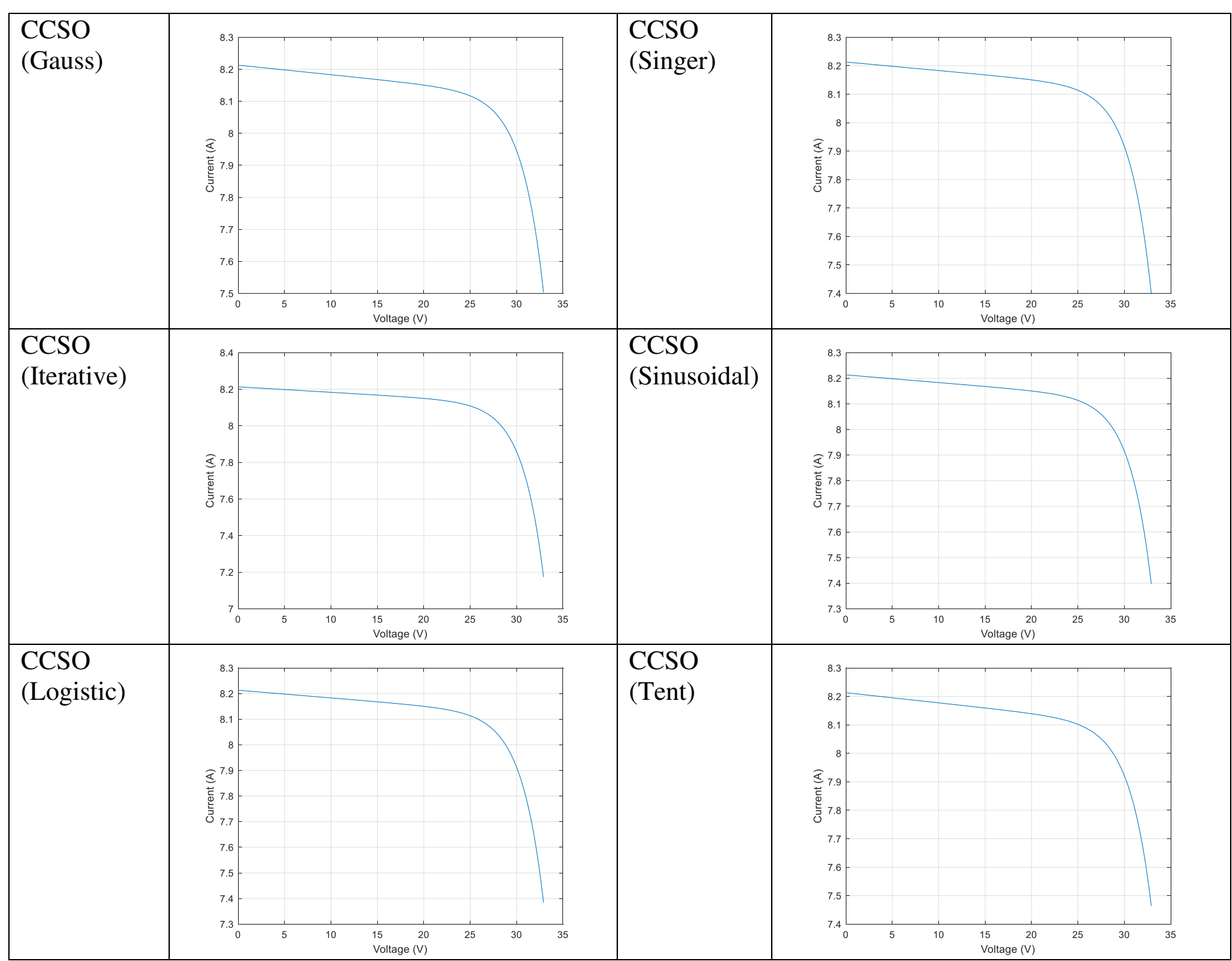

Fig. 10. I-V curves for all the chaotic CSO techniques.

Similarly, the P-V curves under standard test conditions (STC) are also have been plotted in Fig. 11. To prove the consistency of the estimated parameter process by the suggested techniques.

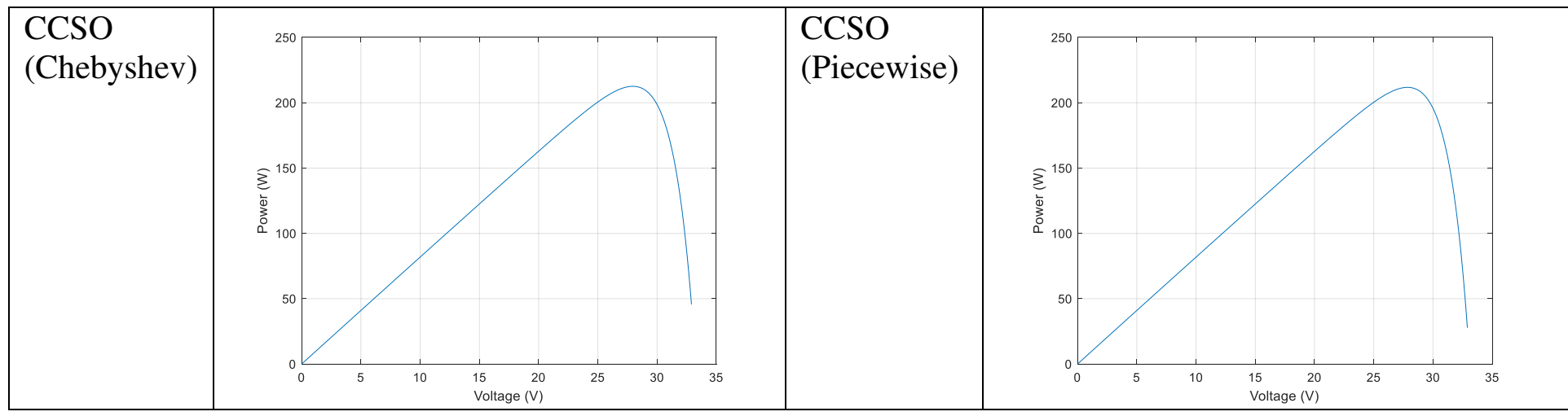




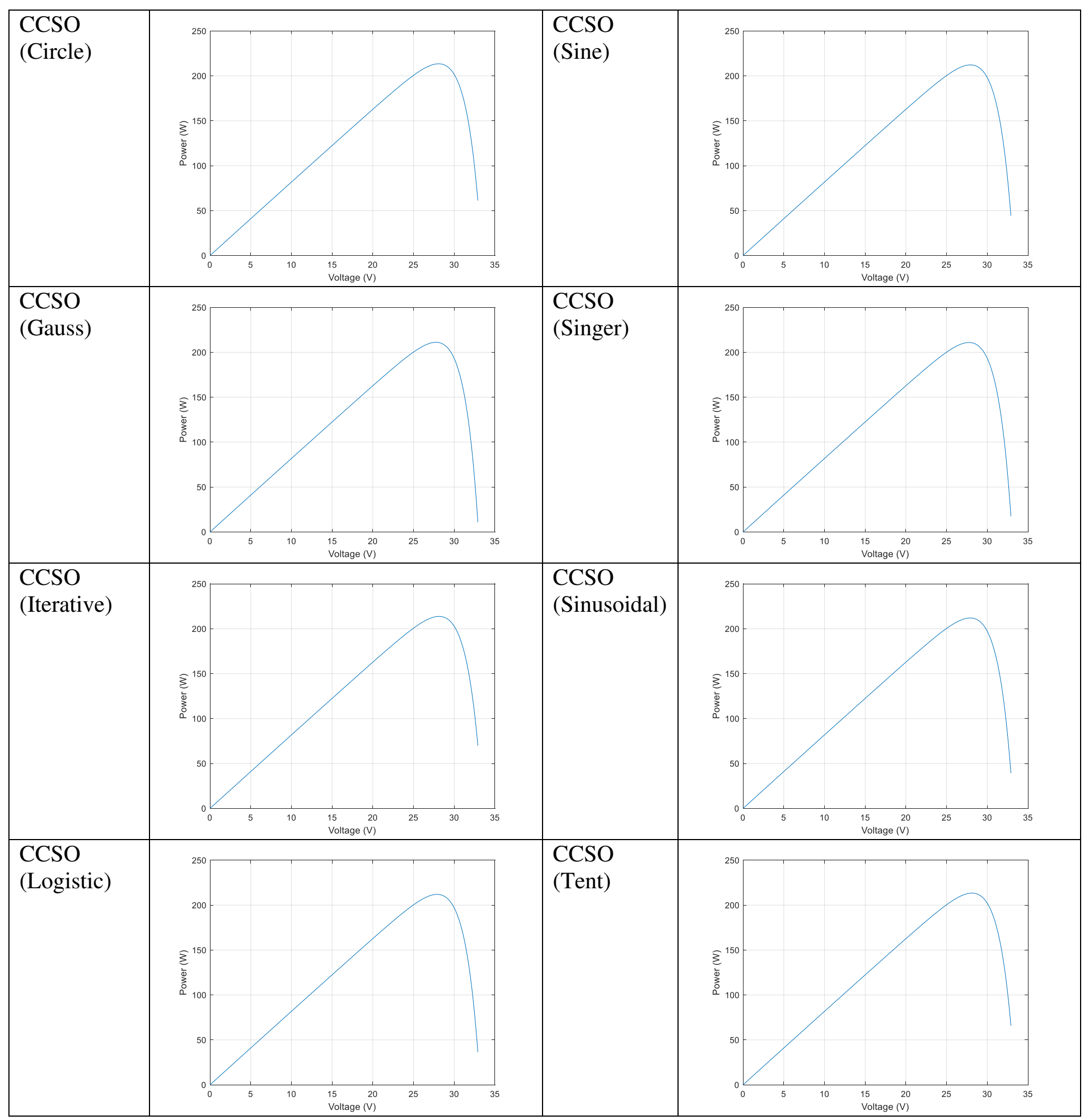

Fig. 11. P-V curves for all the chaotic CSO techniques.

Similar to case study-1, for better validation of the results, the non-parametric tests are also conducted. Initially, the rank-sum test of Wilcoxon is carried out. Table 9(a) and 9(b) lists the calculated p-values and justifies that the performances of all variants of CCSO are significant, with a significance level of $95 \%$. 
Table 9(a). p-values for the Wilcoxon rank-sum test

\begin{tabular}{lllllll}
\hline Algorithms & CSO & DA & ALO & MVO & WOA & GOA \\
\hline CCSO (Chebyshev) & $3.0510 \mathrm{e}-11$ & $2.9785 \mathrm{e}-11$ & $3.0647 \mathrm{e}-11$ & $3.0466 \mathrm{e}-11$ & $3.0161 \mathrm{e}-11$ & $3.0183 \mathrm{e}-11$ \\
CCSO (Circle) & $3.0947 \mathrm{e}-11$ & $2.9112 \mathrm{e}-11$ & $3.0141 \mathrm{e}-11$ & $2.9992 \mathrm{e}-11$ & $3.0598 \mathrm{e}-11$ & $3.0951 \mathrm{e}-11$ \\
CCSO (Gauss) & $3.0128 \mathrm{e}-11$ & $2.9394 \mathrm{e}-11$ & $3.0858 \mathrm{e}-11$ & $3.0104 \mathrm{e}-11$ & $3.0796 \mathrm{e}-11$ & $2.9993 \mathrm{e}-11$ \\
CCSO (Iterative) & $3.0392 \mathrm{e}-11$ & $2.9830 \mathrm{e}-11$ & $3.0571 \mathrm{e}-11$ & $3.0815 \mathrm{e}-11$ & $3.0975 \mathrm{e}-11$ & $3.0597 \mathrm{e}-11$ \\
CCSO (Logistic) & $3.0812 \mathrm{e}-11$ & $2.9502 \mathrm{e}-11$ & $3.0785 \mathrm{e}-11$ & $3.0396 \mathrm{e}-11$ & $3.0249 \mathrm{e}-11$ & $3.0675 \mathrm{e}-11$ \\
CCSO (Piecewise) & $3.0651 \mathrm{e}-11$ & $2.9457 \mathrm{e}-11$ & $3.0438 \mathrm{e}-11$ & $3.0731 \mathrm{e}-11$ & $3.0886 \mathrm{e}-11$ \\
CCSO (Sine) & $3.0166 \mathrm{e}-11$ & $2.9981 \mathrm{e}-11$ & $3.0291 \mathrm{e}-11$ & $3.0901 \mathrm{e}-11$ & $3.0771 \mathrm{e}-11$ \\
WCCSO (Singer) & $3.0449 \mathrm{e}-11$ & $2.9196 \mathrm{e}-11$ & $3.0112 \mathrm{e}-11$ & $3.0584 \mathrm{e}-11$ & $3.0494 \mathrm{e}-11$ & $3.0766 \mathrm{e}-11$ \\
CCSO (Sinusoidal) & $3.0906 \mathrm{e}-11$ & $2.9997 \mathrm{e}-11$ & $3.0537 \mathrm{e}-11$ & $3.0477 \mathrm{e}-11$ & $3.0161 \mathrm{e}-11$ & $3.0269 \mathrm{e}-11$ \\
CCSO (Tent) & $3.0510 \mathrm{e}-11$ & $2.9785 \mathrm{e}-11$ & $3.0647 \mathrm{e}-11$ & $3.0466 \mathrm{e}-11$ & $3.0161 \mathrm{e}-11$ & $3.0183 \mathrm{e}-11$ \\
\hline
\end{tabular}

Table 9(b). p-values for the Wilcoxon rank-sum test

\begin{tabular}{|c|c|c|c|c|c|c|}
\hline Algorithms & $\mathrm{SCA}$ & SSA & $\mathrm{HHO}$ & ASO & CCSO_1 & CCSO_2 \\
\hline CCSO (Chebyshev) & $3.0561 \mathrm{e}-11$ & $3.0047 \mathrm{e}-11$ & $3.0142 \mathrm{e}-11$ & $3.0010 \mathrm{e}-11$ & $3.0161 \mathrm{e}-11$ & $3.0947 \mathrm{e}-11$ \\
\hline CCSO (Circle) & $3.0446 \mathrm{e}-11$ & $2.9985 \mathrm{e}-11$ & $3.0880 \mathrm{e}-11$ & $2.9437 e-11$ & $3.0592 \mathrm{e}-11$ & $3.0199 \mathrm{e}-11$ \\
\hline CCSO (Gauss) & $3.0162 \mathrm{e}-11$ & $2.9753 \mathrm{e}-11$ & $3.0564 \mathrm{e}-11$ & $2.9074 \mathrm{e}-11$ & $3.0148 \mathrm{e}-11$ & $3.0735 \mathrm{e}-11$ \\
\hline CCSO (Logistic) & $3.0471 \mathrm{e}-11$ & $2.9329 \mathrm{e}-11$ & $3.0792 \mathrm{e}-11$ & $2.9756 \mathrm{e}-11$ & $3.0624 \mathrm{e}-11$ & $3.0215 \mathrm{e}-11$ \\
\hline CCSO (Piecewise) & $3.0259 \mathrm{e}-11$ & $2.9195 \mathrm{e}-11$ & $3.0439 \mathrm{e}-11$ & $3.0105 \mathrm{e}-11$ & $3.0334 \mathrm{e}-11$ & $3.0650 \mathrm{e}-11$ \\
\hline CCSO (Sine) & $3.0962 \mathrm{e}-11$ & $3.0108 \mathrm{e}-11$ & $3.0195 \mathrm{e}-11$ & $2.9177 \mathrm{e}-11$ & $3.0849 \mathrm{e}-11$ & $3.0110 \mathrm{e}-11$ \\
\hline CCSO (Tent) & $3.0561 \mathrm{e}-11$ & $3.0047 \mathrm{e}-11$ & $3.0142 \mathrm{e}-11$ & $3.0010 \mathrm{e}-11$ & $3.0294 \mathrm{e}-11$ & $3.0817 \mathrm{e}-11$ \\
\hline
\end{tabular}

Similar to the first case, the next test performed is the Kruskal Wallis test. The outcome graphs are presented in Fig. 12. Shows that the mean ranks of the CCSO techniques are significantly different from the other algorithms validating thus the significances of the results.

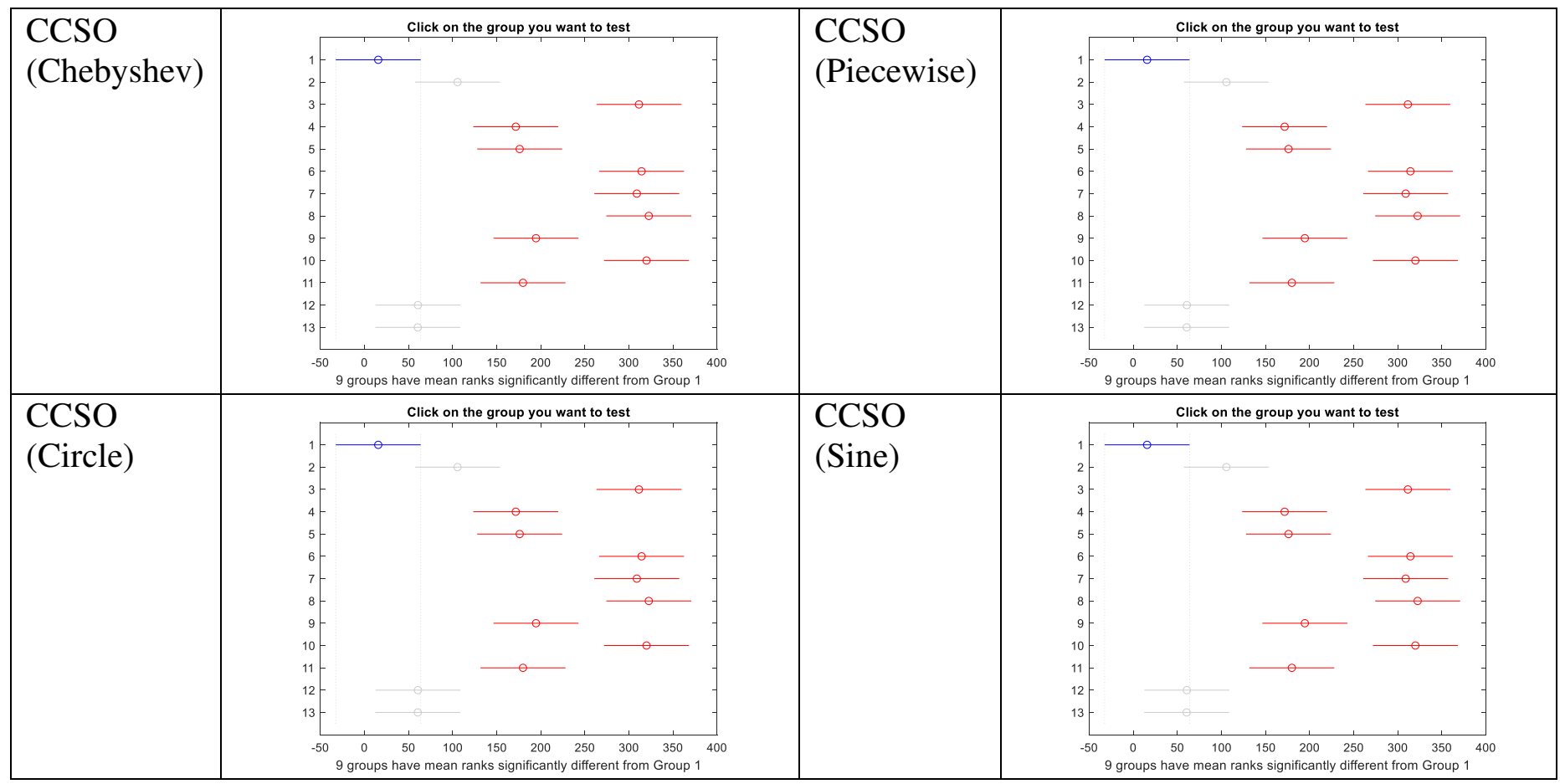




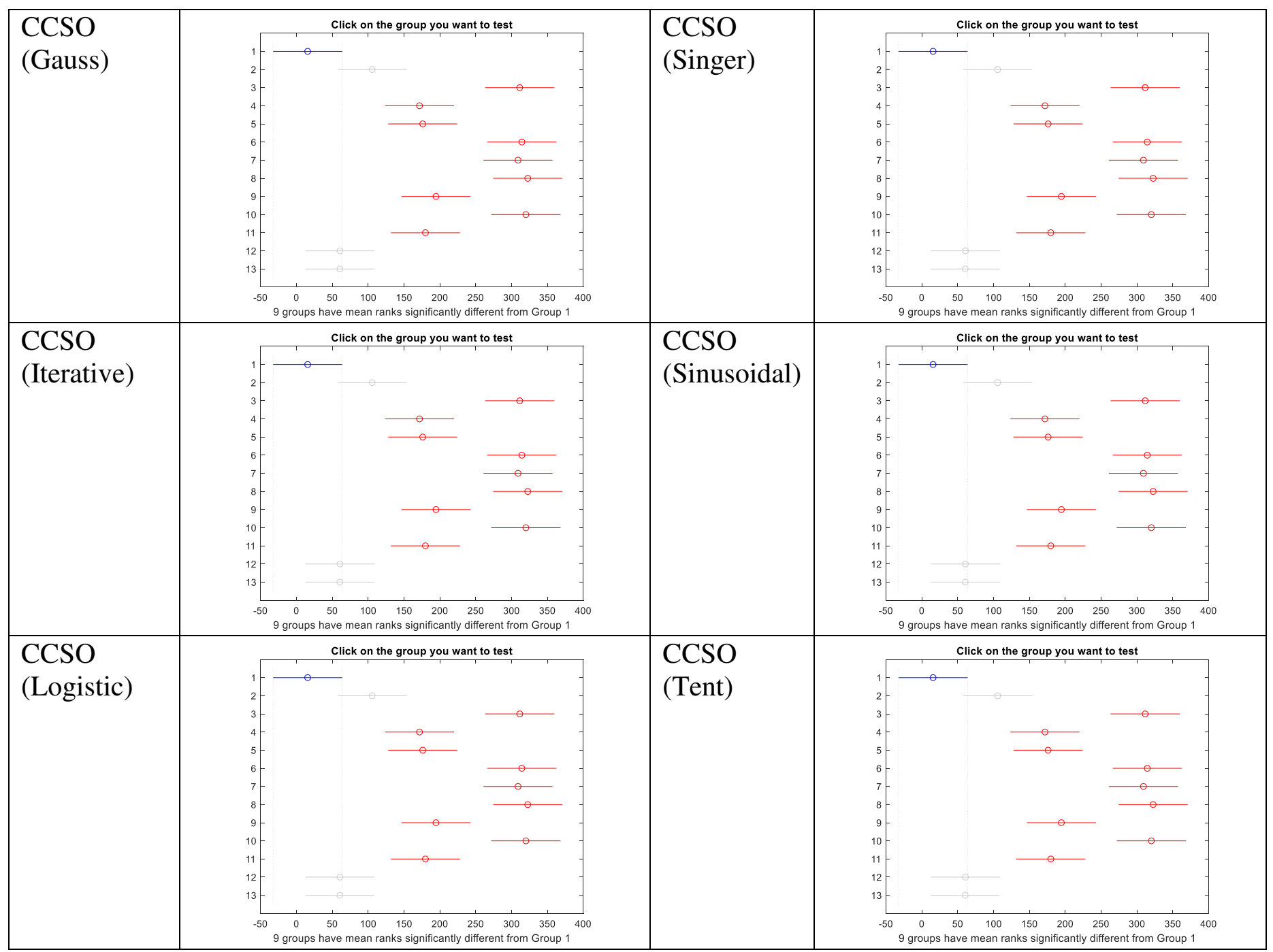

Fig. 12. Kruskal Wallis test diagram for the Kyocera (KC200GT multi-crystal) model results.

On a similar note, the p-values obtained by the Wilcoxon rank test is further evaluated using the Holm-Bonferroni corrections method. The outcome results are presented in Table 10(a) and10(b) which validate the proposed CCSO methods.

Table 10(a). Corrected p-values by Holm-Bonferroni corrections for Wilcoxon rank test.

(Multiply the results with (1.0e-09) and test of significance (h) is 1)

\begin{tabular}{lllllll}
\hline Algorithms & CSO & DA & ALO & MVO & WOA & GOA \\
\hline CCSO (Chebyshev) & 0.1219 & 0.2978 & 0.0611 & 0.1509 & 0.2110 & 0.1810 \\
CCSO (Circle) & 0.0926 & 0.2911 & 0.2099 & 0.2399 & 0.1522 & 0.0619 \\
CCSO (Gauss) & 0.1806 & 0.2907 & 0.0616 & 0.2100 & 0.0917 & 0.2380 \\
CCSO (Iterative) & 0.2117 & 0.2955 & 0.1824 & 0.1224 & 0.0924 & 0.1529 \\
CCSO (Logistic) & 0.2982 & 0.2982 & 0.2404 & 0.1805 & 0.1207 & 0.0906 \\
CCSO (Piecewise) & 0.1218 & 0.2919 & 0.1821 & 0.0920 & 0.0615 & 0.2118 \\
CCSO (Sine) & 0.2409 & 0.2918 & 0.1812 & 0.0923 & 0.1231 & 0.1515 \\
CCSO (Singer) & 0.2108 & 0.2920 & 0.2393 & 0.1525 & 0.1827 & 0.0918 \\
CCSO (Sinusoidal) & 0.0611 & 0.2687 & 0.0914 & 0.1213 & 0.2110 & 0.1810 \\
CCSO (Tent) & 0.2982 & 0.2982 & 0.2404 & 0.1805 & 0.1207 & 0.0906 \\
\hline
\end{tabular}


Table 10(b). Corrected p-values by Holm-Bonferroni corrections for Wilcoxon rank test.

(Multiply the results with (1.0e-09) and test of significance (h) is 1)

\begin{tabular}{lllllll}
\hline Algorithms & SCA & SSA & HHO & ASO & CCSO_1 & CCSO_2 \\
\hline CCSO (Chebyshev) & 0.0915 & 0.2701 & 0.2404 & 0.2978 & 0.2413 & 0.0613 \\
CCSO (Circle) & 0.1808 & 0.2649 & 0.1224 & 0.2911 & 0.1827 & 0.2411 \\
CCSO (Gauss) & 0.1506 & 0.2645 & 0.1206 & 0.2907 & 0.2109 & 0.1223 \\
CCSO (Iterative) & 0.0619 & 0.2685 & 0.2386 & 0.2955 & 0.1233 & 0.2983 \\
CCSO (Logistic) & 0.0604 & 0.2106 & 0.1505 & 0.2704 & 0.1828 & 0.2976 \\
CCSO (Piecewise) & 0.2408 & 0.2919 & 0.1522 & 0.2651 & 0.2723 & 0.1522 \\
CCSO (Sine) & 0.0618 & 0.2698 & 0.2112 & 0.2918 & 0.1231 & 0.3011 \\
CCSO (Singer) & 0.1223 & 0.2920 & 0.0618 & 0.2662 & 0.2114 & 0.1819 \\
CCSO (Sinusoidal) & 0.2932 & 0.2400 & 0.1513 & 0.2932 & 0.1819 & 0.0618 \\
CCSO (Tent) & 0.0604 & 0.2106 & 0.1505 & 0.2704 & 0.2113 & 0.0613 \\
\hline
\end{tabular}

Case 3: The Solarex (MSX-60 poly-crystalline) commercial module is considered a test system. Similar to cases 1 and 2, the unknown parameters of the TDM are identified using the different CCSO methods. The results of the extracted parameters are thus provided in Table 11. As many algorithms are used for comparison.

Table 11. Parameter estimation of TDM utilizing Solarex (MSX-60 poly-crystalline).

\begin{tabular}{|c|c|c|c|c|c|c|c|c|c|}
\hline Algorithms & $\mathrm{I}_{\mathrm{PV}}$ & $\alpha_{1}$ & $\alpha_{2}$ & $\alpha_{3}$ & $\mathrm{R}_{\mathrm{S}}$ & $\mathrm{R}_{\mathrm{sh}}$ & $\mathrm{I}_{01}$ & $\mathrm{I}_{02}$ & $\mathrm{I}_{03}$ \\
\hline CCSO (Chebyshev) & 3.8007 & 1.6604 & 1.7414 & 1.6594 & 0.0670 & 350.2424 & $5.0405 \mathrm{e}-07$ & $4.6675 \mathrm{e}-07$ & $5.3207 \mathrm{e}-07$ \\
\hline CCSO (Circle) & 3.8006 & 1.7181 & 1.7262 & 1.6622 & 0.0630 & 364.9196 & $5.6228 \mathrm{e}-07$ & $5.7694 \mathrm{e}-07$ & $5.8448 \mathrm{e}-07$ \\
\hline CCSO (Gauss) & 3.8006 & 1.7042 & 1.7418 & 1.7418 & 0.0651 & 365.5107 & $4.3119 \mathrm{e}-07$ & $5.2946 \mathrm{e}-07$ & $6.2651 \mathrm{e}-07$ \\
\hline CCSO (Iterative) & 3.8007 & 1.7001 & 1.7067 & 1.7137 & 0.0737 & 357.3770 & $5.2362 \mathrm{e}-07$ & $4.9889 \mathrm{e}-07$ & $4.7401 \mathrm{e}-07$ \\
\hline CCSO (Logistic) & 3.8007 & 1.6789 & 1.7363 & 1.7350 & 0.0757 & 352.1045 & $5.0795 \mathrm{e}-07$ & $4.8644 \mathrm{e}-07$ & $5.0921 \mathrm{e}-07$ \\
\hline CCSO (Piecewise) & 3.8007 & 1.7032 & 1.6968 & 1.7404 & 0.0656 & 369.1128 & $5.2000 \mathrm{e}-07$ & $4.9932 \mathrm{e}-07$ & $5.5763 \mathrm{e}-07$ \\
\hline CCSO (Sine) & 3.8007 & 1.7096 & 1.7483 & 1.6990 & 0.0681 & 351.9238 & $5.4566 \mathrm{e}-07$ & $4.6693 \mathrm{e}-07$ & $5.8948 \mathrm{e}-07$ \\
\hline CCSO (Singer) & 3.8007 & 1.6900 & 1.7097 & 1.6988 & 0.0662 & 348.0949 & $4.6966 \mathrm{e}-07$ & $4.8532 \mathrm{e}-07$ & $5.3252 \mathrm{e}-07$ \\
\hline CCSO (Sinusoidal) & 3.8007 & 1.7169 & 1.7298 & 1.6774 & 0.0727 & 355.8210 & $6.1338 \mathrm{e}-07$ & $5.0430 \mathrm{e}-07$ & $4.2880 \mathrm{e}-07$ \\
\hline CCSO (Tent) & 3.8007 & 1.6979 & 1.7408 & 1.6983 & 0.0672 & 357.1666 & $5.7214 \mathrm{e}-07$ & $5.5199 \mathrm{e}-07$ & $5.9184 \mathrm{e}-07$ \\
\hline CSO [37] & 3.8006 & 1.6632 & 1.7108 & 1.6821 & 0.0603 & 365.4920 & $4.8014 \mathrm{e}-07$ & $5.9008 \mathrm{e}-07$ & $6.4198 \mathrm{e}-07$ \\
\hline CCSO_1 [43] & 9.4112 & 1.6739 & 1.5923 & 1.6000 & 0.0014 & 371.7669 & $1.3795 \mathrm{e}-07$ & $6.4572 \mathrm{e}-07$ & $8.3824 \mathrm{e}-07$ \\
\hline CCSO_2 [44] & 9.4428 & 1.6241 & 1.5914 & 1.6809 & 0.0026 & 303.2168 & $5.0116 \mathrm{e}-07$ & $1.0000 \mathrm{e}-06$ & $1.0748 \mathrm{e}-07$ \\
\hline $\mathrm{DA}[4 \overline{5}]$ & 3.8717 & 1.6284 & 1.5971 & 1.6059 & 0.2154 & 279.7127 & $4.1435 \mathrm{e}-07$ & $4.0480 \mathrm{e}-07$ & $4.6731 \mathrm{e}-07$ \\
\hline ALO [46] & 3.8281 & 1.7267 & 1.7508 & 1.5790 & 0.1536 & 294.9870 & $5.3044 \mathrm{e}-07$ & $4.5884 \mathrm{e}-07$ & $5.0700 \mathrm{e}-07$ \\
\hline MVO [47] & 3.8474 & 1.4381 & 1.3948 & 1.4849 & 0.0250 & 209.2078 & $5.2000 \mathrm{e}-07$ & $2.4568 \mathrm{e}-07$ & $4.4000 \mathrm{e}-07$ \\
\hline WOA [48] & 3.9114 & 1.6193 & 1.6186 & 1.6221 & 0.2614 & 277.0438 & $5.4277 \mathrm{e}-07$ & $5.0518 \mathrm{e}-07$ & $6.1349 \mathrm{e}-07$ \\
\hline GOA [49] & 3.8783 & 1.6348 & 1.7285 & 1.5964 & 0.2935 & 496.4711 & $4.7526 \mathrm{e}-07$ & $4.1047 \mathrm{e}-07$ & $3.8245 \mathrm{e}-07$ \\
\hline SCA [50] & 3.8121 & 1.2484 & 1.3479 & 1.2132 & 0.0175 & 247.1086 & $1.2736 \mathrm{e}-07$ & $1.4829 \mathrm{E}-07$ & $1.6517 \mathrm{E}-07$ \\
\hline SSA [23] & 3.8484 & 1.6147 & 1.5814 & 1.6207 & 0.2069 & 299.8353 & $4.1442 \mathrm{e}-07$ & $3.9549 \mathrm{e}-07$ & $4.3418 \mathrm{e}-07$ \\
\hline HHO [51] & 3.8998 & 1.5594 & 1.6070 & 1.5949 & 0.2314 & 281.2135 & $4.2884 \mathrm{e}-07$ & $5.8137 \mathrm{e}-07$ & $5.2916 \mathrm{e}-07$ \\
\hline ASO [52] & 3.8320 & 1.6011 & 1.6191 & 1.6253 & 0.0818 & 263.7884 & $3.6828 \mathrm{e}-07$ & $4.5886 \mathrm{e}-07$ & $3.5679 \mathrm{e}-07$ \\
\hline
\end{tabular}

The normalized value of parameters (minimum, maximum, mean, and standard deviation) of SSE are represented in Table 12. The range of normalized values lies between 0 and 1 , where 0 refers to the least value and 1 represents the worst value. From the result, it is evident that the CCSO algorithm parameters of SSE achieve the least value for the PV model in comparison with the other algorithms 
Table 12. Normalized statistical measures of the SSE for TDM utilizing Solarex (MSX-60 poly-crystalline)

\begin{tabular}{|c|c|c|c|c|}
\hline Algorithms & Min & Max & Mean & $\begin{array}{l}\text { Standard } \\
\text { Deviation }\end{array}$ \\
\hline CCSO (Chebyshev) & $3.3898 \mathrm{E}-10$ & $2.3394 \mathrm{E}-09$ & $3.2725 \mathrm{E}-09$ & $2.7733 \mathrm{E}-09$ \\
\hline CCSO (Circle) & $1.5136 \mathrm{E}-09$ & $1.2305 \mathrm{E}-09$ & $5.2026 \mathrm{E}-10$ & $5.3502 \mathrm{E}-01$ \\
\hline CCSO (Gauss) & $9.5763 \mathrm{E}-11$ & 1.6185E-09 & $6.4307 \mathrm{E}-10$ & $3.3213 \mathrm{E}-10$ \\
\hline CCSO (Iterative) & $\mathbf{0}$ & 2.0901E-09 & $1.5450 \mathrm{E}-09$ & 1.8079E-09 \\
\hline CCSO (Logistic) & $5.8475 \mathrm{E}-10$ & 1.7062E-09 & $\mathbf{0}$ & $\mathbf{0}$ \\
\hline CCSO (Piecewise) & $9.9322 \mathrm{E}-10$ & $1.3584 \mathrm{E}-09$ & $1.1680 \mathrm{E}-09$ & $5.4549 \mathrm{E}-10$ \\
\hline CCSO (Sine) & $7.5424 \mathrm{E}-10$ & $\mathbf{0}$ & $1.9168 \mathrm{E}-10$ & $1.2274 \mathrm{E}-11$ \\
\hline CCSO (Singer) & $7.1949 \mathrm{E}-10$ & 2.2574E-09 & 1.3309E-09 & $1.1726 \mathrm{E}-09$ \\
\hline CCSO (Sinusoidal) & 7.0593E-10 & $6.6815 \mathrm{E}-10$ & $1.3757 \mathrm{E}-09$ & 3.9134E-10 \\
\hline CCSO (Tent) & $1.9237 \mathrm{E}-10$ & 2.0270E-09 & $1.1896 \mathrm{E}-09$ & $8.4043 \mathrm{E}-10$ \\
\hline CCSO_1 [43] & $9.1502 \mathrm{E}-07$ & $9.4391 \mathrm{E}-07$ & $8.0560 \mathrm{E}-07$ & $9.2832 \mathrm{E}-07$ \\
\hline CCSO_2 [44] & $8.7576 \mathrm{E}-07$ & $9.7598 \mathrm{E}-07$ & 8.6752E-07 & 8.8511E-07 \\
\hline $\mathrm{CSO}[37]$ & $6.9068 \mathrm{E}-10$ & 9.7704E-05 & 7.8263E-05 & $9.0429 \mathrm{E}-05$ \\
\hline DA [45] & $8.8136 \mathrm{E}-01$ & $8.5626 \mathrm{E}-01$ & 8.3795E-01 & 8.8087E-01 \\
\hline ALO [46] & $8.4746 \mathrm{E}-02$ & $6.4116 \mathrm{E}-02$ & 6.6098E-02 & 6.1372E-02 \\
\hline MVO [47] & $9.0678 \mathrm{E}-01$ & $9.3588 \mathrm{E}-01$ & $7.7825 \mathrm{E}-01$ & $9.0614 \mathrm{E}-01$ \\
\hline WOA [48] & 8.5593E-01 & $9.4623 \mathrm{E}-01$ & 7.7612E-01 & 9.5307E-01 \\
\hline GOA [49] & $8.4746 \mathrm{E}-02$ & $9.7208 \mathrm{E}-02$ & 7.8891E-02 & $9.0253 \mathrm{E}-02$ \\
\hline SCA [50] & 8.5593E-01 & $9.6070 \mathrm{E}-02$ & 7.7186E-01 & 8.5921E-01 \\
\hline SSA [23] & $8.4746 \mathrm{E}-02$ & 9.7208E-02 & 7.8891E-02 & $9.0253 \mathrm{E}-02$ \\
\hline HHO [51] & $1.0000 \mathrm{e}+00$ & $1.0000 \mathrm{e}+00$ & $1.0000 \mathrm{e}+00$ & $1.0000 \mathrm{e}+00$ \\
\hline ASO [52] & $9.3220 \mathrm{E}-02$ & $9.2037 \mathrm{E}-01$ & 7.0362E-02 & 7.2202E-02 \\
\hline
\end{tabular}

The convergence curves of the error functions are plotted in Fig.13. The comparison shows that the proposed chaotic chicken swarm techniques are far from the well-known methods reported in the literature.

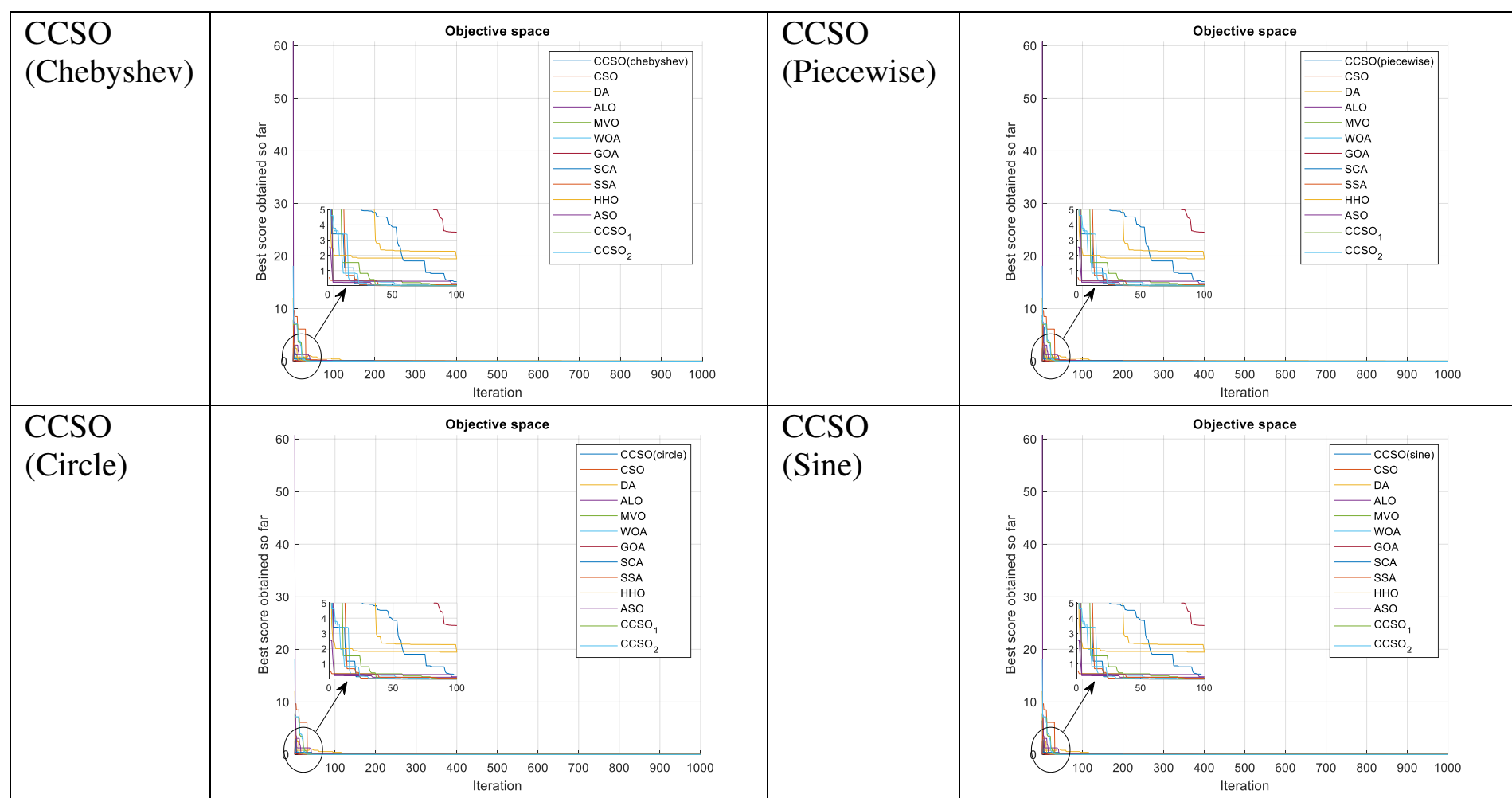




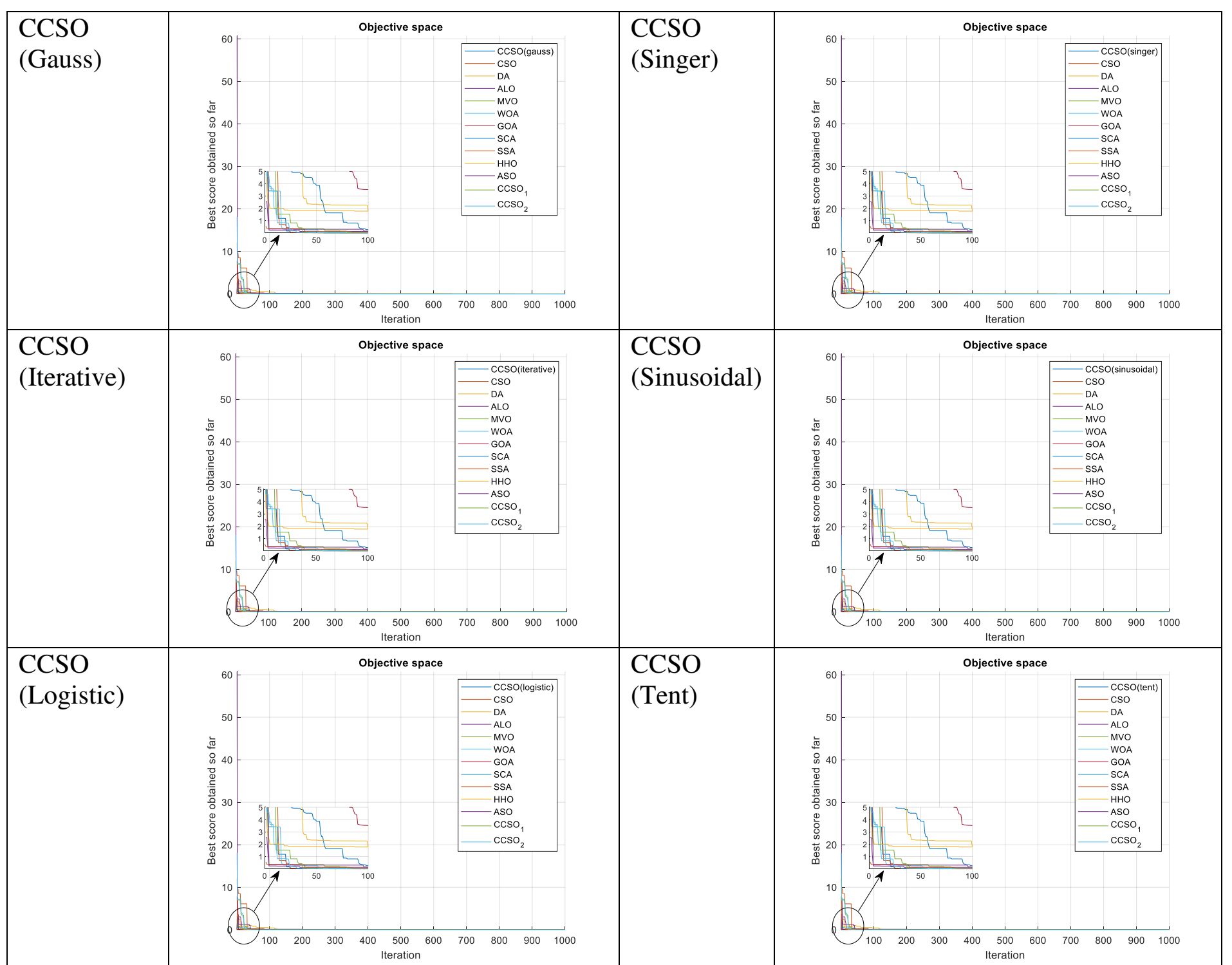

Fig. 13. Convergences curves of each variant of CCSO with other compared algorithms.

Fig. 14. shows the I-V curves of all variants of CCSO. The curves are pretty similar to the ideal characteristic curves of the solar model proving the accuracy of the proposed methodology.

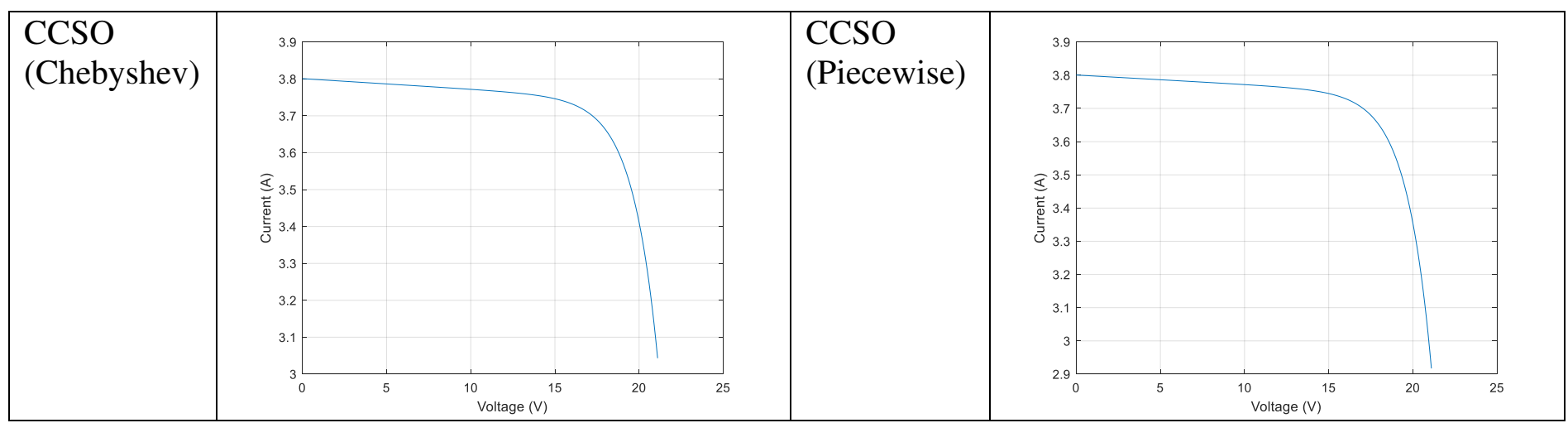




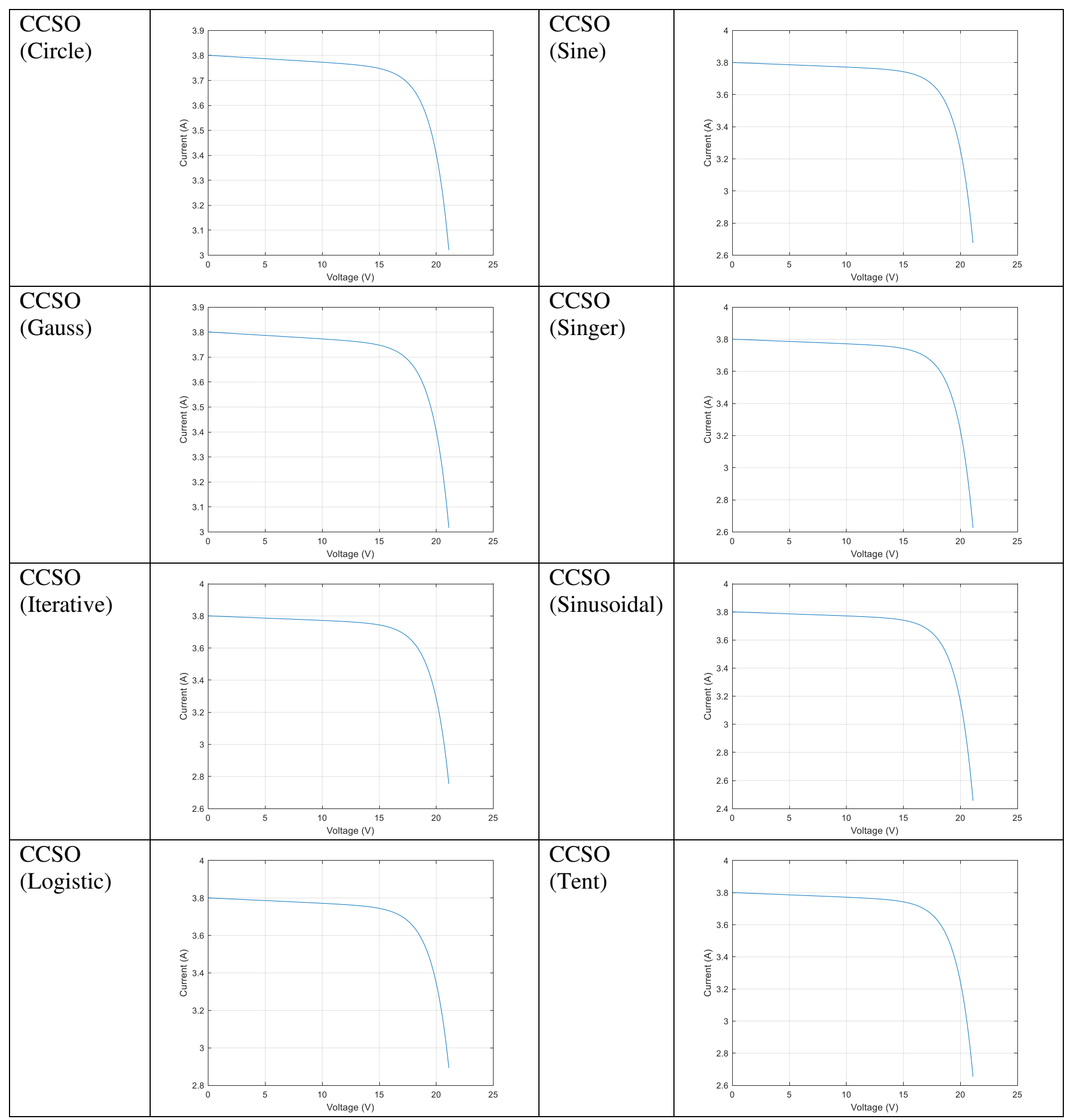

Fig. 14. I-V curves for all the chaotic CSO techniques.

The P-V curves are plotted in Fig. 15. from the estimated parameters of the said model. The results obtained in the graph replicate the original curve. 


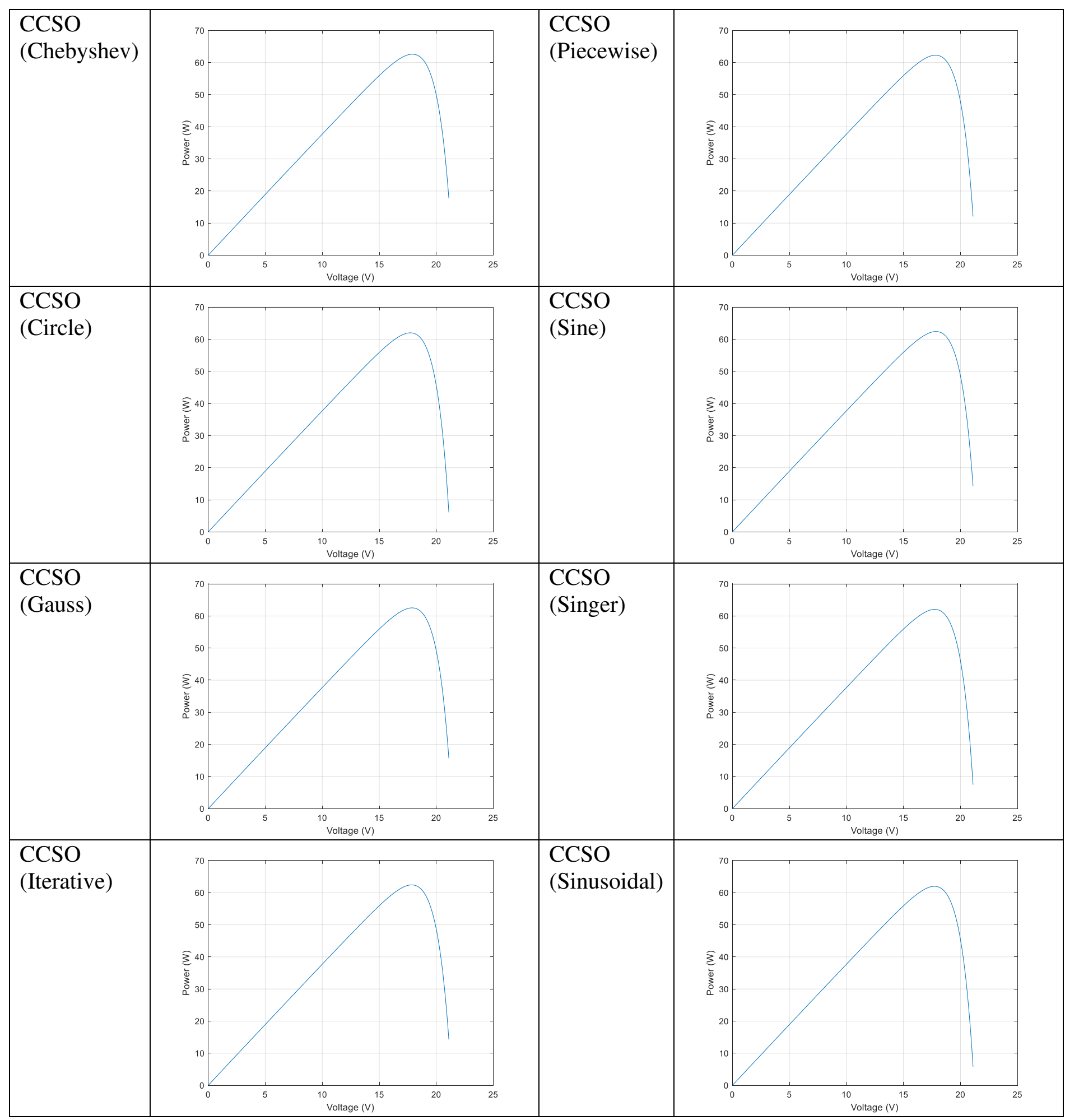




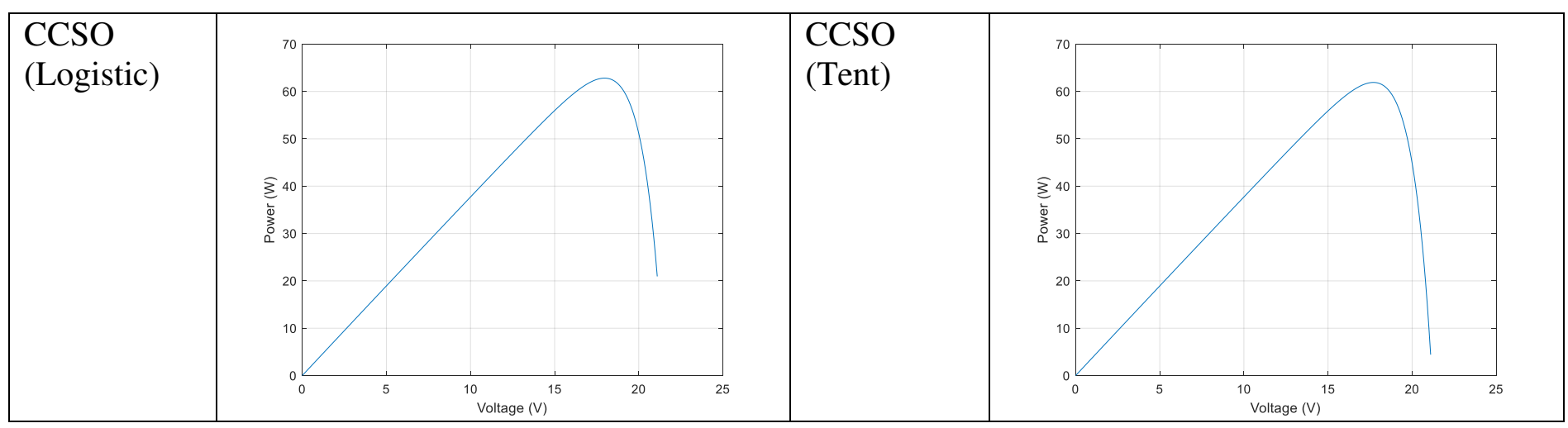

Fig. 15. P-V curves of all variants of CCSO from the estimated parameters.

Similar to test cases 1 and 2 for better validation of the results, the non-parametric tests are conducted. Initially, the rank-sum test of Wilcoxon is carried out. Table 13(a) and 13(b) lists the calculated p-values and justifies that the performances of all variants of CCSO are significant, with a significance level of $95 \%$.

Table 13(a). p-values for the Wilcoxon rank-sum test

\begin{tabular}{|c|c|c|c|c|c|c|}
\hline Algorithms & $\mathrm{CSO}$ & DA & $\mathrm{ALO}$ & MVO & WOA & GOA \\
\hline CCSO (Chebyshev) & $3.0253 \mathrm{e}-11$ & $3.0161 \mathrm{e}-11$ & $2.9947 \mathrm{e}-11$ & $3.0142 \mathrm{e}-11$ & $3.0180 \mathrm{e}-11$ & $2.9921 \mathrm{e}-11$ \\
\hline CCSO (Circle) & $3.0467 \mathrm{e}-11$ & $2.9770 \mathrm{e}-11$ & $3.0259 \mathrm{e}-11$ & $3.0021 \mathrm{e}-11$ & $2.9966 \mathrm{e}-11$ & $2.9175 \mathrm{e}-11$ \\
\hline CCSO (Gauss) & $3.0148 \mathrm{e}-11$ & $3.0516 \mathrm{e}-11$ & $3.0422 \mathrm{e}-11$ & $3.0570 \mathrm{e}-11$ & $3.0719 \mathrm{e}-11$ & $2.9564 \mathrm{e}-11$ \\
\hline CCSO (Iterative) & $3.0856 \mathrm{e}-11$ & $3.0187 \mathrm{e}-11$ & $3.0905 \mathrm{e}-11$ & $3.0164 \mathrm{e}-11$ & $3.0804 \mathrm{e}-11$ & 2.9991e-11 \\
\hline CCSO (Logistic) & $3.0910 \mathrm{e}-11$ & $3.0850 \mathrm{e}-11$ & $3.0611 \mathrm{e}-11$ & $3.0349 \mathrm{e}-11$ & $3.0133 \mathrm{e}-11$ & $3.0042 \mathrm{e}-11$ \\
\hline CCSO (Piecewise) & $3.0619 \mathrm{e}-11$ & $3.0912 \mathrm{e}-11$ & $3.0388 \mathrm{e}-11$ & $3.0949 \mathrm{e}-11$ & $3.0481 \mathrm{e}-11$ & $2.9709 \mathrm{e}-11$ \\
\hline CCSO (Sine) & $3.0321 \mathrm{e}-11$ & $2.9428 \mathrm{e}-11$ & $3.0815 \mathrm{e}-11$ & $3.0073 \mathrm{e}-11$ & $3.0349 \mathrm{e}-11$ & $2.9613 \mathrm{e}-11$ \\
\hline WCCSO (Singer) & $3.0437 \mathrm{e}-11$ & $3.0666 \mathrm{e}-11$ & $3.0803 \mathrm{e}-11$ & $3.0121 \mathrm{e}-11$ & $3.0091 \mathrm{e}-11$ & $2.9381 \mathrm{e}-11$ \\
\hline CCSO (Sinusoidal) & $3.0705 \mathrm{e}-11$ & $3.0009 \mathrm{e}-11$ & $3.0052 \mathrm{e}-11$ & $3.1017 \mathrm{e}-11$ & $2.9914 \mathrm{e}-11$ & $2.9850 \mathrm{e}-11$ \\
\hline CCSO (Tent) & $3.0193 \mathrm{e}-11$ & $3.0061 \mathrm{e}-11$ & $2.9969 \mathrm{e}-11$ & $3.0501 \mathrm{e}-11$ & $3.0801 \mathrm{e}-11$ & $3.0127 \mathrm{e}-11$ \\
\hline
\end{tabular}

Table 13(b). p-values for the Wilcoxon rank-sum test

\begin{tabular}{|c|c|c|c|c|c|c|}
\hline Algorithms & SCA & SSA & $\mathrm{HHO}$ & ASO & CCSO_1 & CCSO_2 \\
\hline CCSO (Chebyshev) & $3.0999 \mathrm{e}-11$ & $3.0104 \mathrm{e}-11$ & $3.0617 \mathrm{e}-11$ & $2.9957 \mathrm{e}-11$ & $3.0871 \mathrm{e}-11$ & $3.0611 \mathrm{e}-11$ \\
\hline CCSO (Circle) & $3.0123 \mathrm{e}-11$ & $3.0597 \mathrm{e}-11$ & $3.0102 \mathrm{e}-11$ & $2.9891 \mathrm{e}-11$ & $3.0152 \mathrm{e}-11$ & $2.9864 \mathrm{e}-11$ \\
\hline CCSO (Gauss) & $3.0357 \mathrm{e}-11$ & $3.0091 \mathrm{e}-11$ & $3.0199 \mathrm{e}-11$ & $2.9530 \mathrm{e}-11$ & $3.0917 \mathrm{e}-11$ & $3.0345 \mathrm{e}-11$ \\
\hline CCSO (Iterative) & $3.0638 \mathrm{e}-11$ & $2.9964 \mathrm{e}-11$ & $2.9983 e-11$ & $2.9204 \mathrm{e}-11$ & $2.9991 \mathrm{e}-11$ & $3.0208 \mathrm{e}-11$ \\
\hline CCSO (Logistic) & $3.0529 \mathrm{e}-11$ & $3.0137 \mathrm{e}-11$ & $3.0544 \mathrm{e}-11$ & $2.9384 \mathrm{e}-11$ & $3.0647 \mathrm{e}-11$ & $3.0911 \mathrm{e}-11$ \\
\hline CCSO (Piecewise) & $3.0246 \mathrm{e}-11$ & $3.0339 \mathrm{e}-11$ & $3.0489 \mathrm{e}-11$ & $2.9901 \mathrm{e}-11$ & $3.0146 \mathrm{e}-11$ & $3.0641 \mathrm{e}-11$ \\
\hline CCSO (Sine) & $3.0814 \mathrm{e}-11$ & $3.0815 \mathrm{e}-11$ & $3.0261 \mathrm{e}-11$ & $2.9407 e-11$ & $3.0333 \mathrm{e}-11$ & $2.9824 \mathrm{e}-11$ \\
\hline WCCSO (Singer) & $3.0551 \mathrm{e}-11$ & $3.0740 \mathrm{e}-11$ & $3.0115 \mathrm{e}-11$ & $2.9755 \mathrm{e}-11$ & $3.0154 \mathrm{e}-11$ & $3.0341 \mathrm{e}-11$ \\
\hline CCSO (Sinusoidal) & $3.0349 \mathrm{e}-11$ & $3.0442 \mathrm{e}-11$ & $3.0591 \mathrm{e}-11$ & $2.9102 \mathrm{e}-11$ & $3.0688 \mathrm{e}-11$ & $3.0007 \mathrm{e}-11$ \\
\hline CCSO (Tent) & $3.0100 \mathrm{e}-11$ & $3.1145 \mathrm{e}-11$ & $3.0102 \mathrm{e}-11$ & $2.9991 \mathrm{e}-11$ & $2.9914 \mathrm{e}-11$ & $3.0016 \mathrm{e}-11$ \\
\hline
\end{tabular}


Similarly as done in the first two test cases, the next test performed is the Kruskal Wallis test.

The outcome graphs are presented in Fig. 16. shows that the mean ranks of the CCSO techniques are significantly different from the other algorithms.

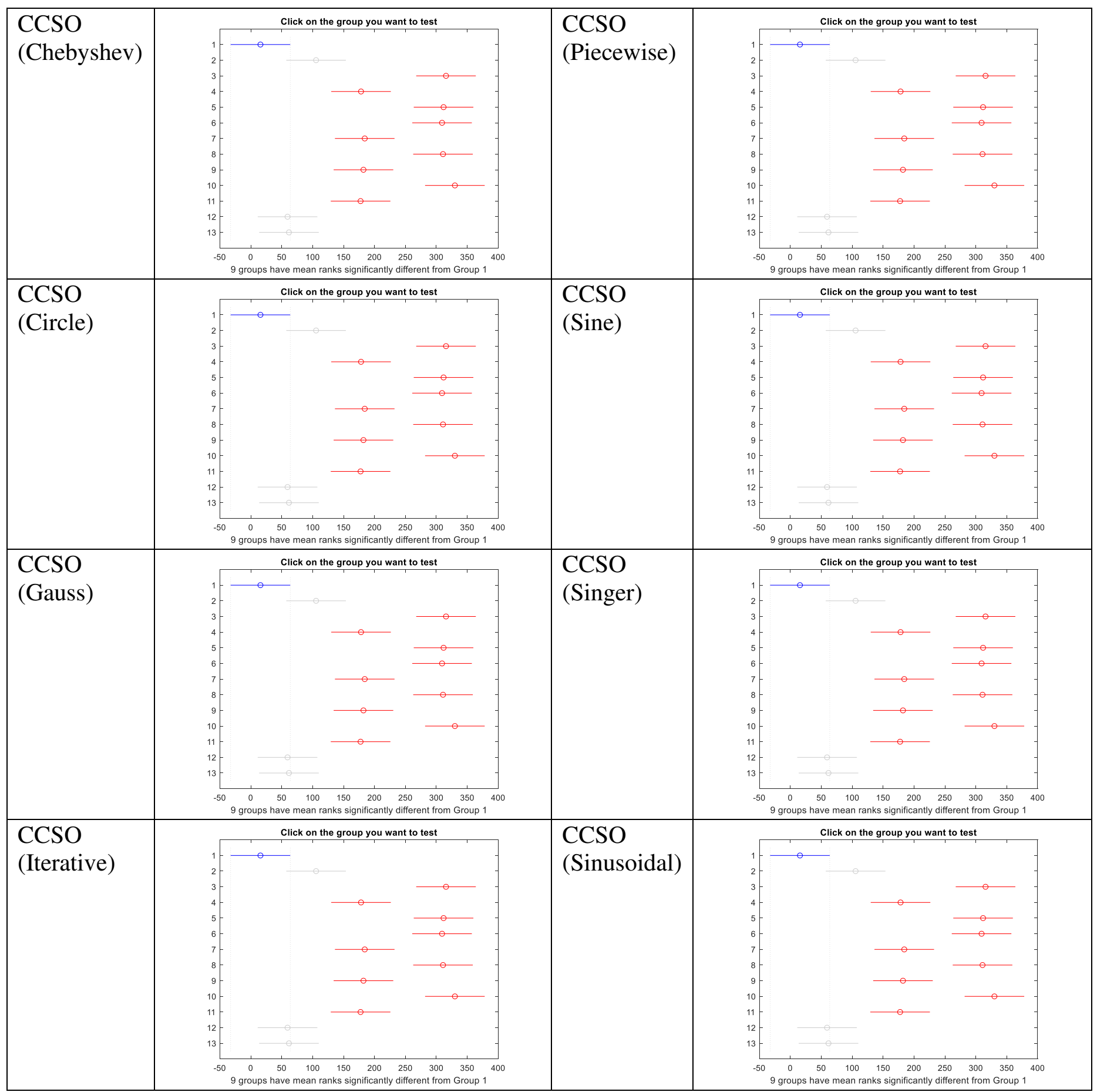




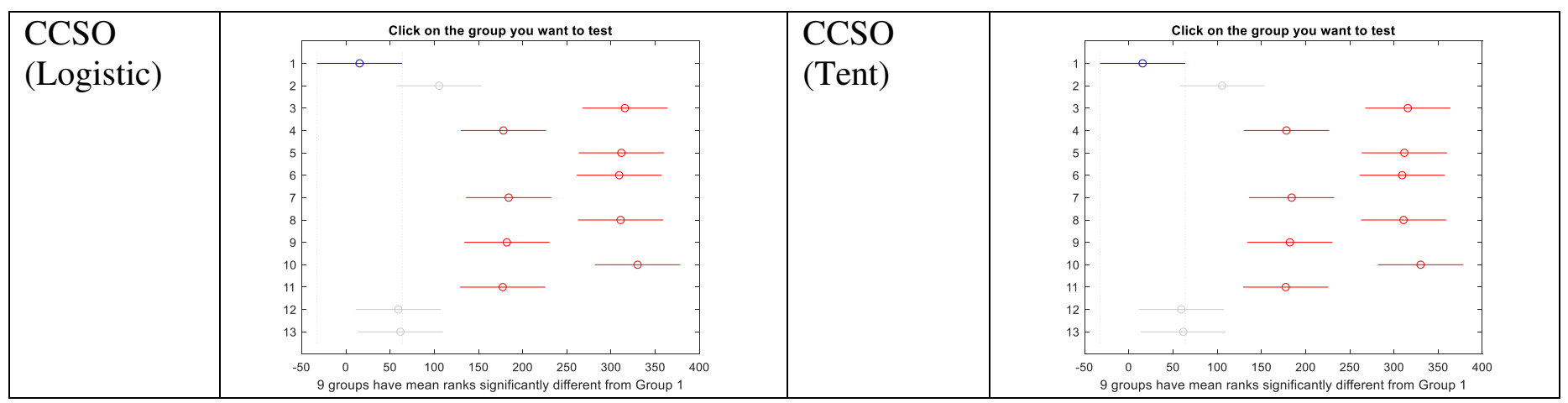

Fig. 16. Kruskal Wallis test diagram for the Solarex (MSX-60 poly-crystalline) model results.

The p-values obtained by the Wilcoxon rank test is further evaluated using the HolmBonferroni corrections method. The outcome results are presented in Table 14(a) and14(b) validate the proposed CCSO algorithms.

Table 14(a). Corrected p-values by Holm-Bonferroni corrections for Wilcoxon rank test. (Multiply the results with (1.0e-09) and test of significance (h) is 1)

\begin{tabular}{lllllll}
\hline Algorithms & CSO & DA & ALO & MVO & WOA & GOA \\
\hline CCSO (Chebyshev) & 0.1207 & 0.1809 & 0.2992 & 0.2107 & 0.1508 & 0.2992 \\
CCSO (Circle) & 0.0908 & 0.2918 & 0.1205 & 0.2098 & 0.2391 & 0.2918 \\
CCSO (Gauss) & 0.2407 & 0.1217 & 0.1518 & 0.0915 & 0.0611 & 0.2953 \\
CCSO (Iterative) & 0.0924 & 0.1810 & 0.0617 & 0.2099 & 0.1226 & 0.2399 \\
CCSO (Logistic) & 0.0911 & 0.0610 & 0.2087 & 0.1794 & 0.2073 & 0.2383 \\
CCSO (Piecewise) & 0.1220 & 0.0919 & 0.2124 & 0.0618 & 0.1823 & 0.2971 \\
CCSO (Sine) & 0.1816 & 0.2941 & 0.0924 & 0.2369 & 0.1516 & 0.2649 \\
CCSO (Singer) & 0.1807 & 0.1222 & 0.0615 & 0.2108 & 0.2678 & 0.2938 \\
CCSO (Sinusoidal) & 0.0918 & 0.2393 & 0.2101 & 0.0614 & 0.2686 & 0.2910 \\
CCSO (Tent) & 0.1205 & 0.0905 & 0.2398 & 0.1799 & 0.2068 & 0.2398
\end{tabular}

Table 14(a). Corrected p-values by Holm-Bonferroni corrections for Wilcoxon rank test.

(Multiply the results with (1.0e-09) and test of significance (h) is 1)

\begin{tabular}{lllllll}
\hline Algorithms & SCA & SSA & HHO & ASO & CCSO_1 & CCSO_2 \\
\hline CCSO (Chebyshev) & 0.0612 & 0.2397 & 0.0908 & 0.2695 & 0.0919 & 0.1513 \\
CCSO (Circle) & 0.1505 & 0.0609 & 0.1801 & 0.2679 & 0.1506 & 0.3275 \\
CCSO (Gauss) & 0.1812 & 0.2661 & 0.2110 & 0.2953 & 0.0614 & 0.2416 \\
CCSO (Iterative) & 0.1509 & 0.2920 & 0.2697 & 0.2920 & 0.2699 & 0.1811 \\
CCSO (Logistic) & 0.1510 & 0.2073 & 0.1213 & 0.2383 & 0.1531 & 0.0618 \\
CCSO (Piecewise) & 0.2691 & 0.2420 & 0.1524 & 0.2971 & 0.3289 & 0.1225 \\
CCSO (Sine) & 0.1214 & 0.0616 & 0.2105 & 0.2941 & 0.1819 & 0.2961 \\
CCSO (Singer) & 0.1522 & 0.0920 & 0.2407 & 0.2938 & 0.2410 & 0.2111 \\
CCSO (Sinusoidal) & 0.1803 & 0.1517 & 0.1218 & 0.2910 & 0.1224 & 0.2991 \\
CCSO (Tent) & 0.1503 & 0.2068 & 0.0604 & 0.2099 & 0.3590 & 0.2999 \\
\hline
\end{tabular}

Thus, it is found that the new swarm techniques prove beneficial to extract successfully the parameters of TDM. A comparative study is carried out with a handful number of benchmark techniques. The convergence characteristics also proved the accuracy of the suggested techniques. The I-V and P-V curves are also near the standard curves under STC conditions. The non-parametric tests are used extensively to validate the results. 


\section{Conclusions and future propositions}

A new chaotic algorithm, namely CCSO, is suggested to resolve worldwide optimization concerns and to extract parameters from different solar cells. Three types of solar PV cells models were considered in this manuscript. The three diode mathematical equivalent model of PV cells was explored in this work. The findings are outlined as follows, based on the results so obtained.

- In this paper, a swarm-based approach is introduced to estimate the undetermined parameters of the three-diode PV models.

- Ten widely popular chaotic maps are used to enhance the performance of chicken swarm optimization (CSO).

- The metaheuristic algorithms use the sum of square error (SSE) as an objective function to obtain the solar cell parameters.

- The performance of the suggested methods is analyzed by comparing them with some of the latest and standard heuristic techniques. The accuracy of the proposed approach is verified through their convergence characteristics.

- The I-V and P-V curves are presented which shows similarity to the curves under STC conditions.

- Further to validate the error result, the non-parametric statistical tests are also executed.

The parameters of the solar cells are obtained assuming standard test conditions (STC). The modelling equations can be modified depending upon different irradiance values and temperature conditions. A weighted sum of square error (WSSE) can be taken up as the new objective to optimize the model parameters. The weights can be adjusted using the several chaotic maps discussed in this article. So far, the work is mostly restricted to single-objective optimization. This can further be extended to define a new multi-objective approach. New advanced techniques can also be proposed for modelling solar cells of even higher dimensions. Moreover, in the future, the proposed techniques may be used to identify the electrical parameters of the fuel cell. Moreover, the optimal sizing of the hybrid renewable energy system (HRES) can also be carried out with the help of this new approach developed.

\section{Conflict of Interest Statement}

The authors at this moment declare that they have no conflict of interest, and any funding agency has not supported this work. 


\section{References}

[1] Alam, D. F., Yousri, D. A., \&Eteiba, M. B. (2015). Flower pollination algorithm based solar PV parameter estimation. Energy Conversion and Management, 101, 410-422.

[2] Allam, D., Yousri, D. A., \&Eteiba, M. B. (2016). Parameters extraction of the three diode model for the multi-crystalline solar cell/module using Moth-Flame Optimization Algorithm. Energy Conversion and Management, 123, 535-548.

[3] Fathy, A., Elaziz, M. A., Sayed, E. T., Olabi, A. G., \&Rezk, H. (2019). Optimal parameter identification of triple-junction photovoltaic panel based on enhanced moth search algorithm. Energy, 188, 116025.

[4] Kumari, P. A., \&Geethanjali, P. (2018). Parameter estimation for photovoltaic system under normal and partial shading conditions: A survey. Renewable and Sustainable Energy Reviews, 84, 1-11.

[5] Hasanien, H. M. (2015). An adaptive control strategy for low voltage ride through capability enhancement of grid-connected photovoltaic power plants. IEEE Transactions on power systems, 31(4), 3230-3237.

[6] Qais, M. H., Hasanien, H. M., \&Alghuwainem, S. (2019). Identification of electrical parameters for three-diode photovoltaic model using analytical and sunflower optimization algorithm. Applied Energy, 250, 109-117.

[7] Bastidas-Rodriguez, J. D., Petrone, G., Ramos-Paja, C. A., \& Spagnuolo, G. (2017). A genetic algorithm for identifying the single diode model parameters of a photovoltaic panel. Mathematics and Computers in Simulation, 131, 38-54.

[8] Biswas, P. P., Suganthan, P. N., Wu, G., \&Amaratunga, G. A. (2019). Parameter estimation of solar cells using datasheet information with the application of an adaptive differential evolution algorithm. Renewable Energy, 132, 425-438.

[9] Ebrahimi, S. M., Salahshour, E., Malekzadeh, M., \& Gordillo, F. (2019). Parameters identification of PV solar cells and modules using flexible particle swarm optimization algorithm. Energy, 179, 358-372.

[10] Chin, V. J., Salam, Z., \&Ishaque, K. (2015). Cell modelling and model parameters estimation techniques for photovoltaic simulator application: A review. Applied Energy, 154, 500-519.

[11] Elazab, O. S., Hasanien, H. M., Alsaidan, I., Abdelaziz, A. Y., \&Muyeen, S. M. (2020). Parameter estimation of three diode photovoltaic model using grasshopper optimization algorithm. Energies, 13(2), 497. 
[12] Mahmoud, Y., \& El-Saadany, E. F. (2014). A photovoltaic model with reduced computational time. IEEE transactions on industrial electronics, 62(6), 3534-3544.

[13] Shannan, N. M. A. A., Yahaya, N. Z., \& Singh, B. (2013, November). Single-diode model and two-diode model of PV modules: A comparison. In 2013 IEEE International Conference on Control System, Computing and Engineering (pp. 210214). IEEE.

[14] Kassis, A., \& Saad, M. (2010). Analysis of multi-crystalline silicon solar cells at low illumination levels using a modified two-diode model. Solar Energy Materials and Solar Cells, 94(12), 2108-2112.

[15] Nishioka, K., Sakitani, N., Uraoka, Y., \& Fuyuki, T. (2007). Analysis of multicrystalline silicon solar cells by modified 3-diode equivalent circuit model taking leakage current through periphery into consideration. Solar energy materials and solar cells, 91(13), 1222-1227.

[16] Elazab, O. S., Hasanien, H. M., Elgendy, M. A., \&Abdeen, A. M. (2018). Parameters estimation of single-and multiple-diode photovoltaic model using whale optimisation algorithm. IET Renewable Power Generation, 12(15), 1755-1761.

[17] Singla, M. K., \& Nijhawan, P. (2021). Triple diode parameter estimation of solar PV cell using hybrid algorithm. International Journal of Environmental Science and Technology, 1-24.

[18] Chenouard, R., \& El-Sehiemy, R. A. (2020). An interval branch and bound global optimization algorithm for parameter estimation of three photovoltaic models. Energy Conversion and Management, 205, 112400.

[19] Saleem, H., \&Karmalkar, S. (2009). An analytical method to extract the physical parameters of a solar cell from four points on the illuminated $\$ J\{-\}$ V $\$$ curve. IEEE Electron Device Letters, 30(4), 349-352.

[20] Mahmoud, Y., Xiao, W., \&Zeineldin, H. H. (2011). A simple approach to modeling and simulation of photovoltaic modules. IEEE transactions on Sustainable Energy, 3(1), 185-186.

[21] Jordehi, A. R. (2016). Parameter estimation of solar photovoltaic (PV) cells: A review. Renewable and Sustainable Energy Reviews, 61, 354-371.

[22] Qais, M. H., Hasanien, H. M., \&Alghuwainem, S. (2020). Parameters extraction of three-diode photovoltaic model using computation and Harris Hawks optimization. Energy, 195, 117040. 
[23] Abbassi, R., Abbassi, A., Heidari, A. A., \&Mirjalili, S. (2019). An efficient salp swarm-inspired algorithm for parameters identification of photovoltaic cell models. Energy Conversion and Management, 179, 362-372.

[24] Derick, M., Rani, C., Rajesh, M., Farrag, M. E., Wang, Y., \&Busawon, K. (2017). An improved optimization technique for estimation of solar photovoltaic parameters. Solar Energy, 157, 116-124.

[25] Allam, D., Yousri, D. A., \&Eteiba, M. B. (2016). Parameters extraction of the three diode model for the multi-crystalline solar cell/module using Moth-Flame Optimization Algorithm. Energy Conversion and Management, 123, 535-548.

[26] Babu, T. S., Ram, J. P., Sangeetha, K., Laudani, A., \& Rajasekar, N. (2016). Parameter extraction of two diode solar PV model using Fireworks algorithm. Solar energy, 140, 265-276.

[27] Jacob, B., Balasubramanian, K., Babu, T. S., \& Rajasekar, N. (2015, February). Parameter extraction of solar PV double diode model using artificial immune system. In 2015 IEEE international conference on signal processing, informatics, communication and energy systems (SPICES) (pp. 1-5). IEEE.

[28] Oliva, D., El Aziz, M. A., \&Hassanien, A. E. (2017). Parameter estimation of photovoltaic cells using an improved chaotic whale optimization algorithm. Applied Energy, 200, 141-154.

[29] Yousri, D., Thanikanti, S. B., Allam, D., Ramachandaramurthy, V. K., \&Eteiba, M. B. (2020). Fractional chaotic ensemble particle swarm optimizer for identifying the single, double, and three diode photovoltaic models' parameters. Energy, 195, 116979.

[30] Mandal, S. (2020). Modeling of photovoltaic systems using modified elephant swarm water search algorithm. International Journal of Modelling and Simulation, 40(6), 436-455.

[31] Lin, X., \& Wu, Y. (2020). Parameters identification of photovoltaic models using niche-based particle swarm optimization in parallel computing architecture. Energy, 196, 117054.

[32] Mingjun, J., \& Huanwen, T. (2004). Application of chaos in simulated annealing. Chaos, Solitons \& Fractals, 21(4), 933-941.

[33] Dos Santos Coelho, L., \& Mariani, V. C. (2008). Use of chaotic sequences in a biologically inspired algorithm for engineering design optimization. Expert Systems with Applications, 34(3), 1905-1913. 
[34] Wilcoxon, F., Katti, S. K., \& Wilcox, R. A. (1970). Critical values and probability levels for the Wilcoxon rank sum test and the Wilcoxon signed rank test. Selected tables in mathematical statistics, 1, 171-259.

[35] Breslow, N. (1970). A generalized Kruskal-Wallis test for comparing K samples subject to unequal patterns of censorship. Biometrika, 57(3), 579-594.

[36] Abdi, H. (2010). Holm's sequential Bonferroni procedure. Encyclopedia of research design, 1(8), 1-8.

[37] Meng, X., Liu, Y., Gao, X., \& Zhang, H. (2014, October). A new bio-inspired algorithm: chicken swarm optimization. In International conference in swarm intelligence (pp. 86-94). Springer, Cham.

[38] Hamidzadeh, J. (2020). Feature selection by using chaotic cuckoo optimization algorithm with levy flight, opposition-based learning and disruption operator. Soft Computing, 1-23.

[39] Sayed, G. I., Hassanien, A. E., \& Azar, A. T. (2019). Feature selection via a novel chaotic crow search algorithm. Neural computing and applications, 31(1), 171-188.

[40] Gandomi, A. H., Yang, X. S., Talatahari, S., \&Alavi, A. H. (2013). Firefly algorithm with chaos. Communications in Nonlinear Science and Numerical Simulation, 18(1), 89-98.

[41] Tian, D., Zhao, X., \& Shi, Z. (2019). Chaotic particle swarm optimization with sigmoid-based acceleration coefficients for numerical function optimization. Swarm and Evolutionary Computation, 51, 100573.

[42] Migallón, H., Jimeno-Morenilla, A., Sánchez-Romero, J. L., \&Belazi, A. (2020). Efficient parallel and fast convergence chaotic Jaya algorithms. Swarm and Evolutionary Computation, 100698.

[43] Ahmed, K., Hassanien, A. E., \& Bhattacharyya, S. (2017, November). A novel chaotic chicken swarm optimization algorithm for feature selection. In 2017 Third International Conference on Research in Computational Intelligence and Communication Networks (ICRCICN) (pp. 259-264). IEEE.

[44] Wang, B., Li, W., Chen, X., \& Chen, H. (2019). Improved chicken swarm algorithms based on chaos theory and its application in wind power interval prediction. Mathematical Problems in Engineering, 2019.

[45] Mirjalili, S. (2016). Dragonfly algorithm: a new meta-heuristic optimization technique for solving single-objective, discrete, and multi-objective problems. Neural Computing and Applications, 27(4), 1053-1073. 
[46] Mirjalili, S. (2015). The ant lion optimizer. Advances in engineering software, 83, 80-98.

[47] Mirjalili, S., Mirjalili, S. M., \& Hatamlou, A. (2016). Multi-verse optimizer: a nature-inspired algorithm for global optimization. Neural Computing and Applications, 27(2), 495-513.

[48] Mirjalili, S., \& Lewis, A. (2016). The whale optimization algorithm. Advances in engineering software, 95, 51-67.

[49] Saremi, S., Mirjalili, S., \& Lewis, A. (2017). Grasshopper optimisation algorithm: theory and application. Advances in Engineering Software, 105, 30-47.

[50] Mirjalili, S. (2016). SCA: a sine cosine algorithm for solving optimization problems. Knowledge-based systems, 96, 120-133.

[51] Heidari, A. A., Mirjalili, S., Faris, H., Aljarah, I., Mafarja, M., \& Chen, H. (2019). Harris hawks optimization: Algorithm and applications. Future generation computer systems, 97, 849-872.

[52] Zhao, W., Wang, L., \& Zhang, Z. (2019). A novel atom search optimization for dispersion coefficient estimation in groundwater. Future Generation Computer Systems, 91, 601-610. 